\title{
Gene co-expression analyses of health(span) across multiple species
}

\author{
$\underline{\text { Steffen Möller }}^{1 *}, \underline{\text { Nadine Saul }}^{2}, \underline{\text { Israel Barrantes }}{ }^{1}, \underline{\text { András Gézsi }}^{3}, \underline{\text { Michael Walter }}^{4}, \underline{\text { Péter }}$ \\ Antal $^{3}$, Georg Fuellen ${ }^{1}$

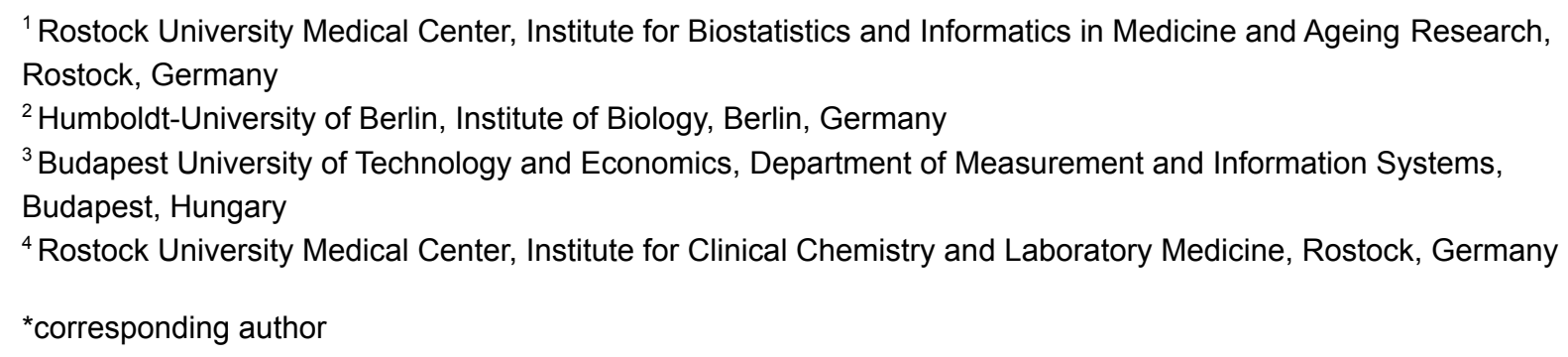

Abstract: Health(span)-related gene clusters/modules were recently identified based on knowledge about the cross-species genetic basis of health, to interpret transcriptomic datasets describing health-related interventions. However, the cross-species comparison of health-related observations reveals a lot of heterogeneity, not least due to widely varying health(span) definitions and study designs, posing a challenge for the exploration of conserved healthspan modules and, specifically, their transfer across species.

To improve the identification and exploration of conserved/transferable healthspan modules, here we apply an established workflow based on gene co-expression network analyses employing GEO/ArrayExpress data for human and animal models, and perform a comprehensive meta-analysis of the resulting modules related to health(span), yielding a small set of health(span) candidate genes, backed by the literature.

For each experiment, WGCNA (weighted gene correlation network analysis) was thus used to infer modules of genes which correlate in their expression with a "health phenotype score" and to determine the most-connected (hub) genes for each such module, and their interactions. After mapping these hub genes to their human orthologs, 12 health(span) genes were identified in at least two species (ACTN3, ANK1, MRPL18, MYL1, PAXIP1, PPP1CA, SCN3B, SDCBP, SKIV2L, TUBG1, TYROBP, WIPF1), for which enrichment analysis by g:profiler finds an association with actin filament-based movement and associated organelles as well as muscular structures.

We conclude that a meta-study of hub genes from co-expression network analyses for the complex phenotype health(span), across multiple species, can yield molecular-mechanistic insights and can direct experimentalists to further investigate the contribution of individual genes and their interactions to health(span).

\section{Introduction}

Health and healthspan are gaining acceptance as central concepts in medicine, with a focus on (multi-)morbidity, aiming to delay the onset of disease and dysfunction for as long as possible. Health is difficult to describe and has different meanings to different people. Aging, and the deterioration of health that comes with it, affects nearly all species. But tissues that enable the systematic study of the underlying molecular processes are more easily available for animal models, especially for invertebrates, coming with further advantages such as 
controlled genetics and environments, and a much shorter lifespan. Thus, aging and healthspan are frequently studied in animal models.

To support aging research, many databases are now available (Tacutu et al., 2018). Gene expression profiles across tissues of aging mice were already presented, e.g., by the AGEMAP (Zahn et al., 2007) project in 2007 and recently by the Aging Atlas Consortium (2020), but there is a lack of such data for healthspan. Adding the dimension of health may amend the identification of molecular markers for aging and further support the identification of health-modulatory compounds (Dönertas et al., 2018).

An increasing number of transcriptomic data sets that can be used to compare young and old individuals are available on public repositories. The concept to derive aging-associated patterns from transcriptome repositories across species (de Magalhães et al., 2009) already led to central elements of aging-related knowledge bases (Tacutu et al., 2012 and 2018). Comprehensive analyses of transcriptome repositories were also expanded towards diseases in the context of aging (van Dam et al., 2012). Yet, as for expression profiles per se, there is a lack of gene expression co-regulation analyses across species with a focus on health(span). A major challenge for polygenic phenotypes in general is the heterogeneity of the underlying gene regulatory landscape (Kotlyar et al., 2019), impeding the use of network-based methods for post-processing, i.e., smoothing, aggregating, and unifying, transcriptomic results (Leiserson et al., 2013; Cowen et al.. 2017). However, the power of the cross-species derivation of conserved co-regulation modules is becoming apparent, see, e.g., the CoCoCoNet database (Lee et al., 2020).

For prominent cellular characteristics of aging, such as cellular senescence, Avelar and coworkers $(\underline{2020})$ demonstrated how to integrate static data from public databases with insights from gene co-expression (https://coxpresdb.jp/, Obayashi et al., 2019). Attempts were also made to use known gene/protein interactions to describe age-induced expression profiles (Faisal and Milenković, 2014). The integration of co-expression data, also across species, could similarly be performed with GeneFriends (van Dam et al., 2015, for human and mouse) for RNA-seq or, for microarray data also with MIM (Adler et al., 2009). The latter also provides provenance information, i.e. the experimental context in which the correlation was found, to plan follow-up experiments.

We recently proposed an operational definition of health (Fuellen et al., 2019) and suggested that it may be applied across species. We then collected data on molecular contributions to health (Möller et al., 2020), with a focus on genetics. With the support of GeneMania (Franz et al. 2018) and the associated tool AutoAnnotate (Kucera et al.. 2016) we then constructed a map of network modules by clustering a functional interaction network of the genes implicated in health. Naturally, aging and health are complex phenotypes for which we still lack the means to single-out and investigate the contribution of individual genes. Any detailed analysis is therefore expected to dissect a list of health-associated genes into gene sets that, in turn, can be understood as parts of the whole (that is health), and these parts are distributed across diseases $\&$ dysfunctions, tissues $\&$ organs, and species. The idea of identifying health-associated molecular patterns is at the root of molecular health research. Our efforts strived for a consensus across the species barrier of worm (Caenorhabditis elegans) and humans and we investigated the transfer of findings from worm as a short-lived 
animal model of health to humans. A consensus in network modules of worm and human was thus determined (Möller et al.. 2020), but it was small in relation to the much larger functional interaction networks that were the starting point for each species. However, functional interaction databases, upon which GeneMania is based, are woefully incomplete. Also, these databases do not usually consider the specific biological context of an interaction, but instead merge interaction data from very heterogeneous sets of experiments (Magger et al.. 2012; Kotlyar et al., 2019).

To harness the power of diverse transcriptomic experiments in the context of health(span), here we present a WGCNA-based meta-study for the exploration and characterization of health(span) related modules. WGCNA co-expression analyses have recently been used in aging research (Li et al., 2019) to identify differences in old vs young and gene expression asymmetries in the brain that develop over time. In our study we integrated a very diverse set of health(span) expression data across species from many different tissues. We manually derived a scoring for all the transcriptome samples we consider, based on a score combining quantitative and qualitative factors that the authors of the experiments provided and refer to it as their "health phenotype score". WGCNA was found to be a competitive tool to find network modules reflecting such kinds of scores (van Dam et al., 2017). Across tissues (or cell lines) and multiple species, this allows the filtering for health-associated modules generated by the WGCNA correlation analysis and thus, the meta-study of health-associated most-connected genes (hubs) and of their interactions, as presented here. We also collected the evidence for the implication of these genes in health(span) from the literature.

\section{Methods}

All sets of transcriptomics experiments in the Gene Expression Omnibus (GEO, Clough and Barrett, 2016) and ArrayExpress (Athar et al., 2019) databases that mention "healthspan" in the title or the description were included, if they featured more than 6 samples and a scale-free network could be derived from their correlation matrix (for the latter, see below). Experiments performed on $C$. elegans were added when these were alternatively annotated with the term "health", to increase the number of datasets for the worm, since "healthspan and "Caenorhabditis elegans"' only finds the single entry E-GEOD-54853. We did not include non-worm experiments with "health" in the title or the description, since the number of matches (specifically for human) turned out to be excessively large. 
Select experiments from

ArrayExpress / GEO
Find modules of genes correlating with health
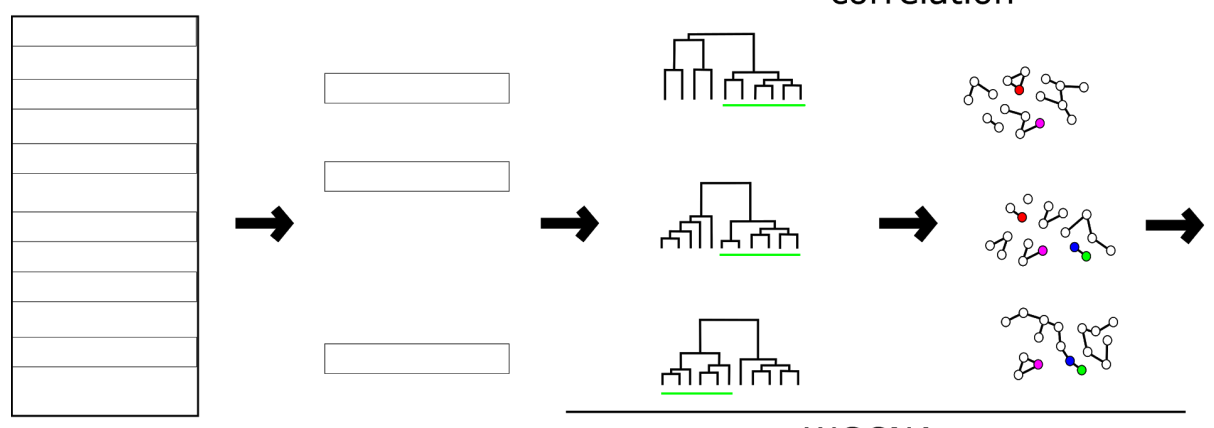

Determine gene interactions from

Determine gene expression consensus across species/experiments correlation

\section{WGCNA}

Figure 1: Workflow to determine cross-species consensus gene correlation networks, and subsequent analyses. WGCNA is applied independently for each selected experiment in ArrayExpress/GEO, defining modules and gene interactions. Gene interactions are filtered by experiment-specific thresholds. For each module, hub genes are retrieved and those with an ortholog found as a hub gene in another species are reported in Table 2. For each module, Table 3 lists the genes that correlate the most with its "eigengene", i.e. that best represent the module's expression pattern across samples.

Each experiment's metadata was inspected to manually derive a score designed to reflect the health status of the individual(s) from which the sample(s) were taken, unless such a score was already given. This "health phenotype score" was manually tailored for each experiment by a custom formula that takes the experiment's factor annotation as an input and thus consistently annotates each sample. This can be inspected in the 'Data_parameters' folder (see Availability). Log-transformation of expression levels was performed if not already performed for the data we retrieved. Table 1 describes the experimental data and metadata which form the input to the following analyses.

Table 1: List of ArrayExpress/GEO files used as input in our study. This table provides an overview of the transcriptomics experiments that were retrieved for this study. Each experiment was processed by a regular WGCNA workflow with unsigned correlation. Interactions were collected for the 30 most connected (hub) genes in each module. The column Modules lists the number of modules found for the experiment that feature an eigengene that correlates (with $P<0.05$ ) with the samples' health phenotype score. Within each module, only interactions with an adjacency value above the $95^{\text {th }}$ percentile of an experiment were considered. The rightmost column lists the number of different hub genes that are paired in any of these interactions. Numbers in parentheses give the number of genes/interactions that could be mapped to ortholog genes in the human; for human data, the number of orthologs in worm are shown. For an interaction, both of the paired genes need to have orthologs assigned; otherwise they were not considered for the count.

\begin{tabular}{|c|c|c|}
\hline Gr Accessio & Description & number of (with orthologs) \\
\hline $\begin{array}{l}\text { p (Technol } \\
\text { ogy) }\end{array}$ & $\begin{array}{l}\text { Analysed } \\
\text { treatment-groups }\end{array}$ & $\begin{array}{c}\text { Modules Interacti Genes } \\
\text { ons }\end{array}$ \\
\hline
\end{tabular}

\begin{tabular}{l|ll} 
H & E-GEOD i) high-fat diet + \\
E & 19102 & 100mg/kg SRT1720, ii) \\
A & (array) & high-fat diet + 30mg/kg \\
L & & SRT1720, iii) high-fat \\
T & & diet, iv) standard \\
H & & AIN-93G diet \\
S & & \\
\hline
\end{tabular}

An activator of Sirt1, SRT1720, extends healthspan and lifespan in diet-induced obese mice; samples: liver tissue from strain C57BL/6J

$\begin{array}{lccc}12 / 3 & 10 & 324 & 28(20) \\ & & (182)\end{array}$


bioRxiv preprint doi: https://doi.org/10.1101/2021.04.08.439030; this version posted April 10, 2021. The copyright holder for this preprint (which was not certified by peer review) is the author/funder, who has granted bioRxiv a license to display the preprint in perpetuity. It is made available under aCC-BY 4.0 International license.

A

E-GEOD

(array)

$\mathrm{O}$

E-GEOD $\frac{-40936}{\text { (array) }}$

i) PGC-1a skeletal

PGC-1a is a transcriptional

muscle specific knockout, coactivator that regulates

ii) PGC-1a skeletal mitochondrial function and is

muscle specific knockout induced by CR; PGC-1a

$+\mathrm{CR}$, iii) WT, iv) WT + mediates mitochondrial, but not

$\mathrm{CR}$

metabolic, changes during

calorie restriction (Finley et al.. 2012)

i) ad libitum diet, muscle Chronic treatment with low dose

tissue, ii) ad libitum diet + of metformin $(0.1 \% \mathrm{w} / \mathrm{w}$ in diet $)$

$0.1 \% \mathrm{w} / \mathrm{w}$ metformin, starting at one year of age

muscle tissue, iii) $40 \%$ extends health and lifespan in

calorically restricted diet, male mice, while a higher dose

muscle tissue, iv) ad

libitum diet, liver tissue,

v) ad libitum diet $+0.1 \%$

w/w metformin, liver

tissue, vi) $40 \%$ calorically

restricted diet, liver tissue

E-GEOD i) standard diet, muscle

-49000 tissue, ii) standard diet

(array) liver tissue, iii) standard

SRT2104, a synthetic small molecule activator of SIRT1,

diet + SRT2104, muscle on a standard diet and

tissue, iv) standard diet + preserves bone and muscle

SRT2104, liver tissue, v) mass

$40 \%$ Caloric restriction,

(Mercken et al., 2014)

muscle tissue, vi) $40 \%$

Caloric restriction, liver

tissue

E-GEOD i) $10 \mathrm{~g} / \mathrm{kg}$

-54853 D-Glucoseamine, ii)

(RNA-se untreated

q)

E-GEOD i) WT, 5 months, liver

-55272 tissue, ii) WT, 24 months,

(array) liver tissue, iii) WT, 5 months, muscle tissue,

iv) WT, 24 months,

muscle tissue, v) WT, 5

months, adipose tissue,

vi) WT, 24 months, adipose tissue, vii)

Myc+/- , 5 months, liver

tissue, viii) Myc+/- , 24

months, liver tissue, ix)

$\mathrm{Myc}+/-, 5$ months,

muscle tissue, $x$ ) Myc+/-

24 months, muscle

tissue, xi) Myc+/- , 5

months, adipose tissue,

xii) Myc+/- , 24 months,

adipose tissue
D-Glucoseamine mimics a ketogenic diet and extends lifespan of aging C57BL/6 mice

The pleiotropic transcription , factor MYC is a proto-oncogene and $\mathrm{Myc}+/$ - heterozygous mice have extended lifespan and improved healthspan

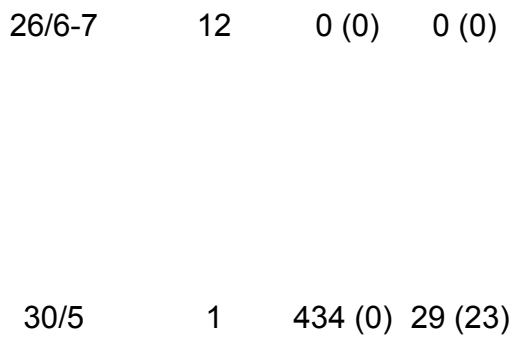

$30 / 5$

no modules

found
$6578 \quad$ weeks, HGPS-/- mutants, healthspan and lifespan in a

(RNA-se ii) 10 weeks, HGPS-/-; mouse model of human

q) NAT10-/- double mutants, accelerated aging syndrome

iii) 10 weeks, NAT10-/- (Hutchinson-Gilford progeria mutants, iv) 10 weeks,

HGPS-/- mutants + 100

$\mathrm{mg} / \mathrm{kg}$ remodelin, v) 104 (Hutchinson-Gilford progeria
syndrome) 


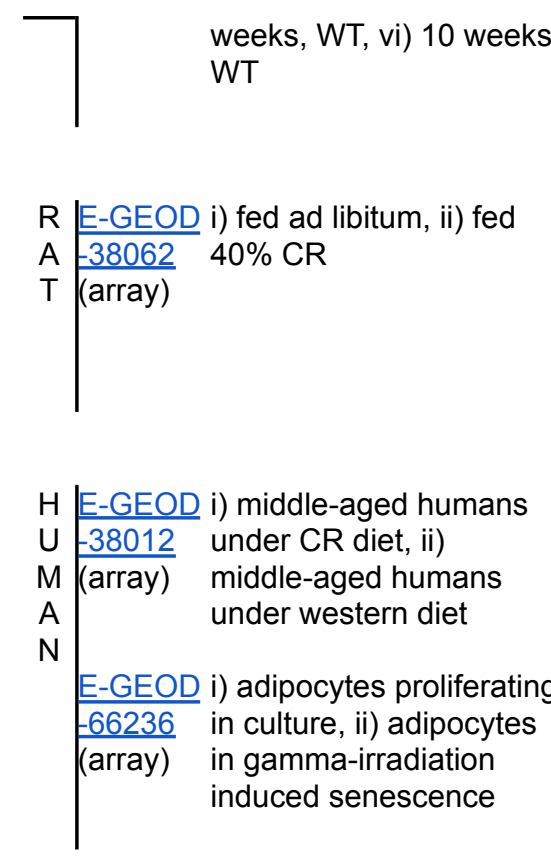

Muscle specimens of rats following a calorie restriction $(40 \%)$ diet vs ad libitum fed rats; age: from 2-27 months (Mercken et al., 2013)

Skeletal muscle specimens of humans following a calorie restriction diet vs humans following a Western diet

Difference between senescent and non-senescent cells in order to develop senolytic drugs

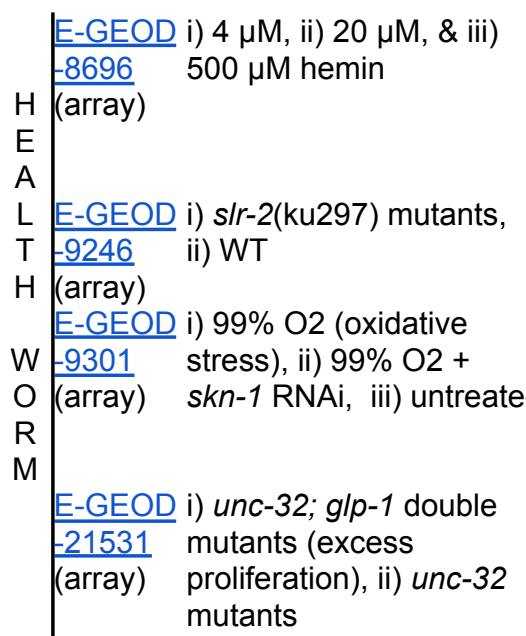

E-GEOD $-30505$ (array)

i) $L 3, W T, E V$, ii) $L 3, W T$, ash-2 RNAi, iii) L3,

g/p-1(e2141ts) mutants, lysine 4 (H3K4); ash-2 $\mathrm{EV}$, iv) L3, g/p-1(e2141ts) knock-down increases lifespan mutants, ash-2 RNAi, v) in a germline dependent day 8, WT, EV, vi) day 8, manner. ash-2 knock-down was WT, ash-2 RNAi, vii) day compared in young and old as $8, g / p-1$ (e2141ts) mutants, EV, viii) day 8 , deficient $(g / p-1)$ mutants g/p-1(e2141ts) mutants, (Greer et al., 2010) ash-2 RNAi

E-GEOD i) $n h r-23 \mathrm{RNAi}$, ii) -32031 untreated (array)

E-GEOD i) L3 WT, ii) L3 nep-1 -32339 mutants, iii) adult WT, iv) (array) adult nep-1 mutants well as in WT and germline

To understand heme transcriptionally regulated by heme should be identified (Rajagopal et al.. 2008) elegans slr-2 (C2H2 Zn-finge protein) mutants at $\mathrm{L} 1$ stage C. elegans treated with oxidative stress in absence and presence response to oxidative stress Analysis of germ cell proliferation in unc-32(e189);glp-1(oz112gf) (excess germ cell proliferation) compared to unc-32(e189) mutants as control (Waters et al., 2010)

The ASH-2 trithorax complex trimethylates histone $\mathrm{H} 3$ at (Greer et al., 2010) Inhibition of $n h r-32$, important for growth and molting, in L2 larvae

Comparison between wild-type ) and nep-1 (homologue of human ECE1 (endothelin-converting enzyme 1) mutant strain
$10 / 5$

$$
8
$$

$\begin{array}{cccc}25 / 10-15 & 2 & \begin{array}{c}405 \\ (324)\end{array} & 28(25) \\ & & & \\ & & & \\ 16 / 8 & 1 & \begin{array}{c}435 \\ (276)\end{array} & 30(24)\end{array}$

$9 / 3$

$\begin{array}{ccc}6 / 3 & 1 & 434 \\ & & (104)\end{array}$

no modules found found

$\begin{array}{ccc}23 / 2-3 & 4 & 854 \\ & & (146)\end{array}$


bioRxiv preprint doi: https://doi.org/10.1101/2021.04.08.439030; this version posted April 10, 2021. The copyright holder for this preprint (which was not certified by peer review) is the author/funder, who has granted bioRxiv a license to display the preprint in perpetuity. It is made available under aCC-BY 4.0 International license.

E-GEOD emt (array) cells with i) mutant
centic touch-recept Huntingtin (128Q) vs normal Huntingtin (19Q) ii) normal Huntingtin (19Q) vs GFP only

torComparison of purified touch receptor neurons expressing mutant Huntingtin N-terminal

mutant Huntingtin $\mathrm{N}$ -

polyGlutamine) with normal Huntingtin N-terminal fragment

E-GEOD i) WT, ii) WT + TAP -36494 (tobacco acid

(RNA-se pyrophosphatase), iii)

The RDE-10/RDE-11 complex triggers RNAi induced mRNA

q) rde-10 mutant, iv) rde-10 target mRNA in C. elegans mutant + TAP, v) rde-11 (Yang et al., 2012) mutant, vi) rde-11 mutant + TAP)

E-GEOD centrifuged at i) $1 \mathrm{~g}$, ii) $5 \mathrm{~g}$, Worms spun in centrifuge at $-38877$ iii) $10 \mathrm{~g}$, iv) $15 \mathrm{~g} \quad$ elevated $\mathrm{g}$ values (array)

E-GEOD i) rsd-2 (yp10) mutants, Effects of transgeneration aging $-4045925^{\circ} \mathrm{C}$, late generation, ii) studied in early and late (array) $\quad r s d-2$ (yp10) mutants, 25 generation $r s d-2$ and $r s d-6$ ${ }^{\circ} \mathrm{C}$, early generation, iii) mutants at the restrictive rsd-2 (pk3307) mutants, temperature of $25^{\circ} \mathrm{C}$ and the $25^{\circ} \mathrm{C}$, late generation, iv) permissive temperature of $20^{\circ} \mathrm{C}$ rsd-2 (pk3307) mutants,

$25^{\circ} \mathrm{C}$, early generation, $\mathrm{v}$ ) rsd-6 (pk3300) mutants, $25^{\circ} \mathrm{C}$, late generation, vi) rsd-6 (pk3300) mutants, $25^{\circ} \mathrm{C}$, early generation, vii ) rsd-2 (yp10) mutants, $20{ }^{\circ} \mathrm{C}$, late generation, viii) $r s d-2$ (yp10) mutants, $20{ }^{\circ} \mathrm{C}$, early generation, ix) $r s d-2$ (pk3307) mutants, $20^{\circ} \mathrm{C}$, late generation, $\mathrm{x}$ ) $r s d-2$ (pk3307) mutants, $20^{\circ} \mathrm{C}$, early generation, xi) $r s d-6$ (pk3300) mutants, $20^{\circ} \mathrm{C}$, late generation, xii) $r s d-6$ (pk3300) mutants, $20^{\circ} \mathrm{C}$, early generation

E-GEOD i) fed with E.coli OP50 for The lactic acid bacteria -421923 days or ii) 10 days, iii) Lactobacillus rhamnosus (array) fed with Lactobacillus (CNCM I-3690) increase worm's rhamnosus CNCM I-3690lifespan by antioxidative actions for 3 days or iv) 10 days, v) fed with Lactobacillus rhamnosus CNCM I-4317 for 3 days or vi) 10 days glp-1(q224ts) mutants, iii) $n h r-114 /$ HNF4 protects germline WT untreated, iv) WT + stem cells from dietary tryptophan

E-GEOD i) day 1 , ii) day $1+100$ -46051 nM rotenone, iii) day 5 , (RNA-se iv) day $5+100 \mathrm{nM}$ rotenone, v) day $10, \mathrm{vi})$ metabolites. The downregulation of $n h r-114$ results in germline defects and sterility, which depends on tryptophan. Sterile glp-1 mutants are used for comparison. animals

Deep sequencing of endogenous mRNA from Caenorhabditis elegans in the presence and absence of found found

no modules found no modules found 


\begin{tabular}{|c|c|c|c|c|c|c|}
\hline q) & $\begin{array}{l}\text { day } 10+100 \mathrm{nM} \\
\text { rotenone, vii) day } 20, \text { viii) } \\
\text { day } 20+100 \mathrm{nM} \\
\text { rotenone }\end{array}$ & $\begin{array}{l}\text { rotenone at } 4 \text { different time } \\
\text { points ( } \underline{\text { Schmeisser et al., 2013) }}\end{array}$ & & & & \\
\hline$\frac{\text { E-GEOD }}{\frac{-51502}{\text { (array) }}}$ & $\begin{array}{l}\text { i) genetically activated } \\
\text { beta-catenin, ii) WT }\end{array}$ & $\begin{array}{l}\text { Use of an activated beta-catenin } \\
\text { to identify Wnt/beta-catenin } \\
\text { pathway target genes (Jackson } \\
\text { et al., 2014) }\end{array}$ & $6 / 3$ & 3 & $\begin{array}{l}1302 \\
(112)\end{array}$ & $86(27)$ \\
\hline$\frac{\text { E-GEOD }}{\text { (array) }}$ & $\begin{array}{l}\text { i) WT, ii) rsks-1 mutants, } \\
\text { iii) daf-2 mutants, iv) } \\
\text { daf-2;rsks-1 double } \\
\text { mutants, v) } \\
\text { daf-16;daf-2;rsks-1 triple } \\
\text { mutants }\end{array}$ & $\begin{array}{l}\text { Synergistic lifespan extension in } \\
\text { daf-2;rsks- } 1 \text { double mutants } \\
\text { requires DAF-16 and the } \\
\text { germline was identified as the } \\
\text { key tissue for this synergistic } \\
\text { longevity (Chen et al., 2013) }\end{array}$ & $47 / 9-10$ & & $\begin{array}{l}\text { no mo } \\
\text { fou }\end{array}$ & $\begin{array}{l}\text { odules } \\
\text { und }\end{array}$ \\
\hline $\begin{array}{l}\frac{\text { E-GEOD }}{-54853} \\
\text { (RNA-se } \\
\text { q) }\end{array}$ & $\begin{array}{l}\text { i) } 100 \mu \mathrm{M} \\
\text { D-Glucosamine, ii) } \\
\text { untreated }\end{array}$ & $\begin{array}{l}\text { D-Glucosamine extends C. } \\
\text { elegans lifespan by impairing } \\
\text { glucose metabolism to activate } \\
\text { AMP-activated protein kinase }\end{array}$ & $12 / 6$ & 2 & $870(0)$ & $60(20)$ \\
\hline $\begin{array}{l}\frac{\text { E-GEOD }}{-57739} \\
\text { (RNA-se } \\
\text { q) }\end{array}$ & $\begin{array}{l}\text { i) WT + standard food } \\
\text { (OP50), ii) WT }+S \text {. } \\
\text { aureus, iii) hlh- } 30 \\
\text { mutants + OP } 50, \text { iv) } \\
\text { hlh- } 30 \text { mutants }+S . \\
\text { aureus }\end{array}$ & $\begin{array}{l}\text { HLH-30/TFEB is a transcription } \\
\text { factor in the host response to } \\
\text { infections and regulates the } \\
\text { transcription of cytoprotective } \\
\text { and antimicrobial genes (Visvikis } \\
\text { et al.,2014) }\end{array}$ & $8 / 2$ & & $\begin{array}{l}685 \\
(55)\end{array}$ & $90(28)$ \\
\hline$\frac{\text { E-GEOD }}{\frac{85342}{(\text { array) }}}$ & i) 5-fluorouracil, ii) DMSO & $\begin{array}{l}\text { Treatment with } 5 \text {-fluorouracil } \\
\text { inhibits growth of } P \text {. aeruginosa } \\
\text { and reduces pyoverdine } \\
\text { biosynthesis }\end{array}$ & $6 / 3$ & & \multicolumn{2}{|c|}{$\begin{array}{l}\text { no modules } \\
\text { found }\end{array}$} \\
\hline$\frac{\text { E-MEXP- }}{\frac{479}{(\text { array) }}}$ & $\begin{array}{l}\text { i) fed with standard food } \\
\text { for } 12 \mathrm{~h} \text { or ii) } 24 \mathrm{~h} \text {, iii) fed } \\
\text { with Drechmeria } \\
\text { coniospora for } 12 \mathrm{~h} \text { or iv) } \\
24 \mathrm{~h}\end{array}$ & $\begin{array}{l}\text { Exposure to the fungal pathogen } \\
\text { Drechmeria coniospora for } 12 \\
\text { and } 24 \text { hours (Pujol et al., 2008) }\end{array}$ & $64 / 16$ & & \multicolumn{2}{|c|}{$\begin{array}{l}\text { no modules } \\
\text { found }\end{array}$} \\
\hline$\frac{\text { E-MTAB- }}{\frac{1333}{\text { (array) }}}$ & $\begin{array}{l}\text { pash- } 1(\mathrm{mj} 100) \text { mutants at } \\
\text { restrictive temperature } \\
\left(25^{\circ} \mathrm{C}\right) \text { for i) } 0 \text {, ii) } 6 \text {, iii) } 12 \\
\text { or iv) } 24 \text { hours, } \\
\text { pash- } 1 \text { (mj } 100) \text {; } \\
\text { pash-1::gfp mutants at } 25 \\
{ }^{\circ} \mathrm{C} \text { for v) } 0, \text { vi) } 6 \text {, vii) } 12 \text { or } \\
\text { viii) } 24 \text { hours }\end{array}$ & $\begin{array}{l}\text { tReversible inactivation of } \\
\text { miRNA synthesis via } \\
\text { 2DGCR8/pash-1 conditional } \\
\text { mutants (Lehrbach et al., 2012) }\end{array}$ & $24 / 3$ & 6 & $\begin{array}{l}1715 \\
(440)\end{array}$ & $119(58)$ \\
\hline$\frac{\text { E-MEXP- }}{\frac{1808}{(\text { array) }}}$ & $\begin{array}{l}\text { i) strain DR1350, ii) strain } \\
\text { DR1350 + dauer } \\
\text { pheromone, iii) WT N2, } \\
\text { iv) WT N2 + dauer } \\
\text { pheromone }\end{array}$ & $\begin{array}{l}\text { Wild type isolates treated with } \\
\text { dauer larva-inducing pheromone } \\
\text { (Harvey et al., 2009) }\end{array}$ & $12 / 3$ & & \multicolumn{2}{|c|}{$\begin{array}{l}\text { no modules } \\
\text { found }\end{array}$} \\
\hline$\frac{\text { E-MEXP- }}{1810}$ & $\begin{array}{l}\text { i) strain RIL-14, ii) strain } \\
\text { RIL-14 + dauer } \\
\text { pheromone, iii) strain } \\
\text { RIL-17, iv) strain RIL-17 } \\
\text { + dauer pheromone }\end{array}$ & $\begin{array}{l}\text { Wild type isolates treated with } \\
\text { dauer larva-inducing pheromone }\end{array}$ & $12 / 3$ & 6 & $\begin{array}{c}261 \\
(108)\end{array}$ & $65(37)$ \\
\hline
\end{tabular}

1 total: total samples in this experiment; per group: samples per treatment-group (biological replicates) 


\section{RNA-seq data re-analysis}

Gene expression levels were typically not available for the RNA-seq data. Therefore, the RNA-seq datasets were all reanalyzed based on the raw data by the following protocol. All target RNA-seq datasets were retrieved from the European Nucleotide Archive (Leinonen et al., 2011), and the corresponding FASTQ files were filtered for Illumina adapters, phage PhiX sequences and quality (Phred score over 25) using BBTools version 38.49 (Bushnell et al.. 2017). Gene expression was then quantified for each RNA-seq run. To this end, the filtered outputs were mapped against the corresponding target genomes from the Ensembl database release 98 (Yates et al., 2019), using the STAR program version 2.7.3a (Dobin et al., 2013). This program also enabled us to assign uniquely mapped reads to individual genes from the short read alignments. Finally, the mapped read counts were normalized as transcripts per million (Li et al., 2010).

\section{Network analysis}

For each experiment, gene interactions are derived from their pairwise Pearson-correlation of gene expression across samples with the WGCNA (Langfelder and Horvath, 2008; Zhao et al., 2010) R package. The WGCNA analysis was performed for undirected interactions.

Parameters were set as instructed by the WGCNA standard protocol, as follows. For every experiment the cutHeight was manually set to remove outliers and the exponent/power was manually determined to ensure that the network is a scale-free network (see below). An experiment is skipped if that is not possible and then marked with "no modules found" in Table 1. For RNA-seq, prior to the removal of outliers, low-count genes were removed by a manual setting of the parameter cutHeight so that the separation of the samples reflects their phenotypes and could no longer be improved, based on the clustering of the genes by expression data with the R function hclust as performed as part of the WGCNA protocol.

In an attempt to make the correlation networks of different experiments more similar to each other with respect to the number of connections that may be expected for each gene, we adhered to the WGCNA protocol that proposes to apply an experiment-specific exponent to the correlation coefficients (WGCNA calls it "power", which it is, but not in the context of the power law mentioned below) to strengthen the differences in the correlation data. Therefore, this power is chosen, for each experiment, just large enough so that in the derived correlation network, the fraction of genes that have $k$-many interactions with other genes is proportional to $k^{-\gamma}$ with $\gamma$ being a small positive parameter. Networks with that property are called scale-free; the parameter $\gamma$ describes how quickly this fraction gets smaller when the number of connections increases. Genes with a high number of connections are rare in scale-free networks, but they exist, and these "hub" genes are considered highly influential on the expression levels of genes in that module. Further, we filtered for modules that are associated with the health(span) phenotype (see next paragraph), and the hub genes are likely to also have a strong effect on this phenotype.

Only network modules whose WGCNA eigengene correlated with the "phenotypic health score" ( $p$-value $<0.05$ ) were retained further. Then, the 30 genes (see the WGCNA tutorial https://horvath.genetics.ucla.edu/html/CoexpressionNetwork/Rpackages/WGCNA/Tutorials/) most connected in a module according to the WGCNA softConnectivity function were considered for subsequent consensus analyses, and called "hub" genes hereafter. Besides 
the modules, output of the WGCNA workflow is the topological overlap matrix with a quantitative description (termed adjacency) of all interactions between any pair of genes of an experiment. For each experiment, we determined a threshold at the $95 \%$ quantile of all the adjacency values. Only gene interactions with an adjacency above that experiment-wide threshold contribute to our analysis of interactions of genes in the health-associated modules. For the 30 hub genes, all pairwise interactions above that experiment-wide $95 \%$ quantile were thus exported. These interactions were then subjected to a pan-module search for consensus genes and consensus interactions, also across species by considering orthologs, presented in Tables 2 and 4. Orthologs were determined based on Ensembl version 101 (Yates et al., 2019).

Further, for each health-associated module, the 30 genes correlating the strongest with the module's eigengene (reflecting average module behavior, also called "module membership" in WGCNA) were retrieved. Those found in at least two species are presented in Table 3. The correlation is taken in relation to the eigengene, and not in relation to the health phenotype score. Either would be fine for a ranking of the hub genes within a module, and the ranking is expected to be identical for the genes most central to a module. However, our particular interest was to abstract from the phenotypes of the experiment and thus utilize the WGCNA-performed modularization to influence the ranking. This is assumed to be particularly useful for experiments with multiple health-associated modules, each of which we expect to focus on a different aspect of health and for which hence also the genes should be ranked differently, to help analyzing that particular module most appropriately, and without any particularities pertaining to the health phenotype score. Multiple probesets describing the same gene, or its splice variants, were not distinguished and mapped to the same human gene, resulting in genes interacting with themselves. Such self-interactions were removed.

\section{Network figures}

The network figures were created with the $\mathrm{R}$ igraph package. A spring-embedding layout was chosen for the plots and manually refined. Figure 2 shows an overview on all hub genes from Table 2, their direct interactions and genes found in any species that connect to at least two hub genes. Additionally, Figures 2a-d in the Supplement were prepared separately for each species, i.e. they show only interactions from modules that WGCNA identified for an experiment based on samples from that species. Input to these supplement figures are the hub genes from Table 2 and all genes that are reachable from the hub genes which are no more than two transitions away. All interactions between the selected (reachable) genes were also added. The resulting graphs were simplified with the igraph minimum spanning tree implementation that maintains the connectivity of the graph but removes all redundant paths between genes. The spanning tree retains the stronger of two alternative paths between genes. A gene connected to a hub gene with a low adjacency value will thus lose that direct link if it is correlating strongly with another gene that has a strong correlation with that hub gene. Hub genes were determined from within WGCNA considering all interactions, not only the ones above the 95th percentile. Hub genes that are strongly connected for experiments in one species may not be equally dominating in another species. This and the competitive effect on directly connected hub genes (one cross-species, the other only observed for one species) imposed by the spanning tree give the impression that the 
cross-species consensus hub genes are marginalized in Supplemental Figures 2a-d, albeit these graphs are seeded from the consensus hub genes and their interactions.

\section{Results}

We analysed all experiments listed in Table 1 with WGCNA. This analysis provided a modularization by an expression-based clustering of genes and allowed to describe the association of each module with the "health phenotype score". WGCNA also quantified the strength of gene correlations and determined hub genes for each module. We identified 12 genes (Table 2) that are among the 30 hub genes in health(span)-associated modules from at least two species. In total (Supplemental Table 1), 658 different genes were found among these top-30 hub genes of all modules as determined by WGCNA. An interaction network of the genes from Table 1, based on correlation of gene expression, is presented in Figure 2.

Table 2: Hub genes in health-associated WGCNA network modules, found in at least two species. Orthologs were mapped to the human gene name using Ensembl. The human gene names also correspond to the names in mouse and rat, whereas the names of the orthologs in worms based on the Ensembl database are given in brackets.

\begin{tabular}{|c|c|c|c|c|}
\hline $\begin{array}{l}\text { Gene } \\
\text { human } \\
\text { (worm) }\end{array}$ & $\begin{array}{l}\text { Human } \\
\text { Mouse }\end{array}$ & Worn & & Description in context of Healthspan \\
\hline$\frac{\text { ACTN3 }}{(\underline{\text { atn-1) }}}$ & & $x$ & $x$ & $\begin{array}{l}\text { Expressed in muscle, known marker for healthspan and athletes' } \\
\text { muscle phenotypes (Pickering and Kiely, 2018). Localized to Z-discs, } \\
\text { anchoring to actin filaments. }\end{array}$ \\
\hline$\frac{\text { ANK1 }}{(\underline{\text { unc-44 }})}$ & $x$ & & $x$ & 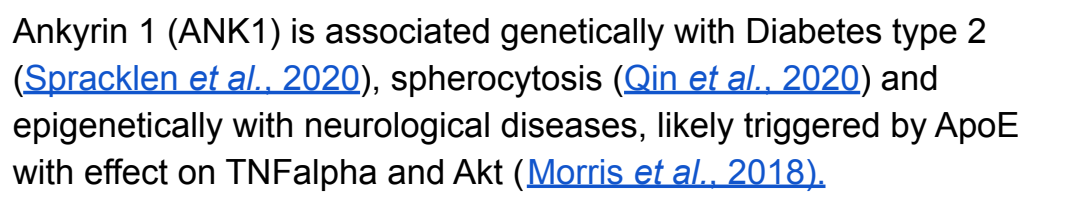 \\
\hline$\frac{\text { MRPL18 }}{(\underline{\mathrm{mrpl}-18})}$ & $x$ & & $x$ & $\begin{array}{l}\text { The mitochondrial ribosomal protein L18 (MRPL18) is involved in the } \\
\text { cytosolic stress response and promotes the translation of Hsp70 } \\
\text { (Zhang et al.. 2015) }\end{array}$ \\
\hline $\begin{array}{l}\text { MYL1 } \\
\underline{\underline{\mathrm{mlc}-6}} \& \text { \&lc })\end{array}$ & $x$ & $x$ & & $\begin{array}{l}\text { MYL1 encodes the myosin light chain } 1 \text { expressed in fast-twitch } \\
\text { skeletal muscle fibers (Stuart et al., 2016). Human ageing is } \\
\text { associated with lower MYL1 content and higher MYL3 content } \\
\text { (Cobley et al., 2016). }\end{array}$ \\
\hline$\frac{\text { PAXIP1 }}{(\text { pis-1) }}$ & $x$ & & $x$ & $\begin{array}{l}\text { The PAX interacting protein } 1 \text { (PAXIP1) contributes to DNA repair } \\
\text { and correlates with breast cancer staging (De Gregoriis et al., 2017). }\end{array}$ \\
\hline $\begin{array}{l}\text { PPP1CA } \\
\underline{\text { C06A1. }} \\
\underline{3} \& 26 \\
\text { others) }\end{array}$ & $x$ & & $x$ & $\begin{array}{l}\text { PPP1CA is one of three catalytic subunits of the serine/threonine } \\
\text { specific protein phosphatase } 1 \text { (PP1), which is known to be involved } \\
\text { in the regulation of glycogen metabolism, cell division, muscle } \\
\text { contractility and protein synthesis (Ceuleman and Bollen, 2004). } \\
\text { PPP1CA itself is linked to diverse tumor entities (Castro et al.. 2007, } \\
\text { Sun et al., 2019) and is involved in ERK/MAPK signaling ( } \text { Sun et al., }\end{array}$ \\
\hline
\end{tabular}


$\underline{\mathrm{SCN} 3 \mathrm{~B}}$

$(-)$

$\underline{\text { SDCBP }}$

(skih-2) $\underline{\text { SKIV2L }}$

2019), TGF $\beta$ signaling (Korrodi-Gregório et al.. 2014), Ras signaling and Ras-induced senescence (Ruiz et al., 2008), spermatogenesis (Silva et al..2014) as well as in tau hyperphosphorylation leading to Alzheimer's disease (Banzhaf-Strathmann et al. 2014).

The sodium voltage-gated channel beta subunit 3 (SCN3B) controls electrolytes and contributes to the pacemaking in the heart and has an effect on intracellular trafficking (Ishikawa et al.. 2012). It also suppresses senescence and apoptosis via its interaction with p53 and thus, is considered to be an oncogenic factor (Li et al., 2020).

x Syntenin-1 (formerly Syndecan(SDC)-binding protein) regulates autophagy (Rajesh et al..2011) and together with Syndecan contributes to exosome formation (Baietti et al., 2012) also in cancer cells (Fares et al.. 2017).

The Ski2-like RNA helicase (SKIV2L) is part of the Super killer (SKI) complex and involved in mRNA degradation, DNA-RNA hybrid control, and telomere stability (Herrera-Moyano et al., 2020). SKIV2L is also known to contribute to inflammatory bowel disease (Vardi et al.. 2018) and macular degeneration (Shuai et al., 2017).

Furthermore, SKIV2L features antiviral capacities and plays a role in innate immunity (Schott and Garcia-Blanco, 2020) associated with RNA exosomes (Eckard et al. .2014).

TUBG1 encodes the tubulin gamma 1 protein, which, when mutated, can lead to brain malformations (Alvarado-Kristensson, 2018) with clinical features such as motor and intellectual disabilities and epilepsy. Moreover, TUBG1 is involved in tumor diseases, as shown for breast cancer (Blanco et al., 2015), lung cancer (Maounis et al.. 2012) and medulloblastomas (Caracciolo et al., 2010).

\section{TYROBP $\quad x \quad x$}

$(-)$

The transmembrane immune signaling adaptor TYROBP is considered to be involved in Alzheimer's disease (Ma et al.. 2015; Pottier et al., 2016) and as a target of TERC in inflammatory processes (Liu et al. 2019). In addition, TYROBP is suggested as a prognostic marker for gastric cancer and renal cell carcinoma ( $\underline{\text { Wu et }}$ al.. 2020; Jiang et al.. 2020).

\section{$\underline{\text { WIPF1 }}$

The WAS/WASL interacting protein family member 1 (WIPF1) regulates actin, phagocytosis, and neurotransmission and is among the top- 3 genes upregulated by caloric restriction in the hypothalamus of wild-type mice (Stranahan et al. .2012). Furthermore, overexpression of WIPF1, triggered by BRAF-mutation activated MAP kinase pathway, promotes aggressiveness of thyroid cancer and thus acts like an oncoprotein (Zhang et al., 2017). Its oncoprotein character was also described for pancreatic 
adenocarcinoma (Pan et al.. 2018) as well as breast cancer, glioma and colorectal cancer (Staub et al., 2009).

Table 3: Genes correlating the strongest with the module's eigengene (quantifying module membership) in at least two species. Genes in this table are among the top-30 of the module membership and found in experiments of at least two species. The gene name is marked in bold if that gene was listed as a hub gene in Table 2. The column "Consensus Correlation" flags "positive" (or "negative") to refer to an observed positive (or negative) correlation with the "health phenotype score" when the gene is upregulated. "mixed" indicates that the experiments did not yield a consensus direction of correlation. Supplement Table 1 extends this list to all genes that appear in the top 30 of modules of two or more experiments. The "\#Experiments" column indicates the number of experiments with a module for which the gene was identified as a member.

\begin{tabular}{|c|c|c|c|c|c|c|c|}
\hline Gene & & $\begin{array}{l}\text { Consensus } \\
\text { Correlation }\end{array}$ & $\begin{array}{c}\text { \#Experiment } \\
s\end{array}$ & Human & Mouse & Rat & Worm \\
\hline AC068831.7 & vps-33.2 & negative & 2 & & negative & & negative \\
\hline ADAM10 & sup-17 & mixed & 2 & & negative & & positive \\
\hline APBB1IP & mig-10 & mixed & 2 & & negative & & positive \\
\hline CEBPB & cebp-1 & mixed & 2 & & negative & positive & \\
\hline CREBBP & $\mathrm{cbp}-1$ & negative & 3 & & negative & & negative \\
\hline EIF3F & eif-3.F & positive & 2 & & positive & & positive \\
\hline INTS12 & F53H1.4 & mixed & 2 & & negative & & positive \\
\hline KPNA3 & ima-3 & mixed & 2 & & negative & & positive \\
\hline MEX3C & mex-3 & negative & 2 & negative & & & negative \\
\hline MRPL19 & mrpl-19 & mixed & 2 & & positive & & negative \\
\hline MYL1 & mlc-6 & positive & 2 & positive & & positive & \\
\hline PAXIP1 & pis-1 & positive & 2 & & positive & & positive \\
\hline PCNX2 & B0511.12 & negative & 2 & & negative & & negative \\
\hline PPP1CA & C06A1.3 & mixed & 4 & positive & & & mixed \\
\hline PPP1CB & $g s p-1$ & positive & 2 & & & positive & positive \\
\hline PPP2R3C & - & negative & 2 & negative & negative & & \\
\hline RAB2A & unc-108 & negative & 2 & & negative & & negative \\
\hline RAB31 & - & negative & 2 & & negative & negative & \\
\hline RPL29 & rpl-29 & positive & 2 & & positive & positive & \\
\hline RTN2 & - & mixed & 2 & positive & negative & & \\
\hline RYR1 & unc-68 & positive & 2 & positive & positive & & \\
\hline SCN3B & - & positive & 2 & & positive & positive & \\
\hline SIX4 & ceh-32 & negative & 2 & & negative & & negative \\
\hline SNRPD1 & snr-3 & negative & 2 & & negative & & negative \\
\hline
\end{tabular}




\begin{tabular}{|c|c|c|c|c|c|c|c|}
\hline TMEM70 & F32D8.5 & mixed & 2 & & positive & & negative \\
\hline TUBG1 & - & mixed & 2 & positive & negative & & \\
\hline WIPF1 & wip-1 & negative & 3 & & negative & & negative \\
\hline ZC3H15 & F27D4.4 & negative & 2 & & negative & & negative \\
\hline SQSTM1 & sqst-1 & negative & 3 & & negative & negative & negative \\
\hline
\end{tabular}

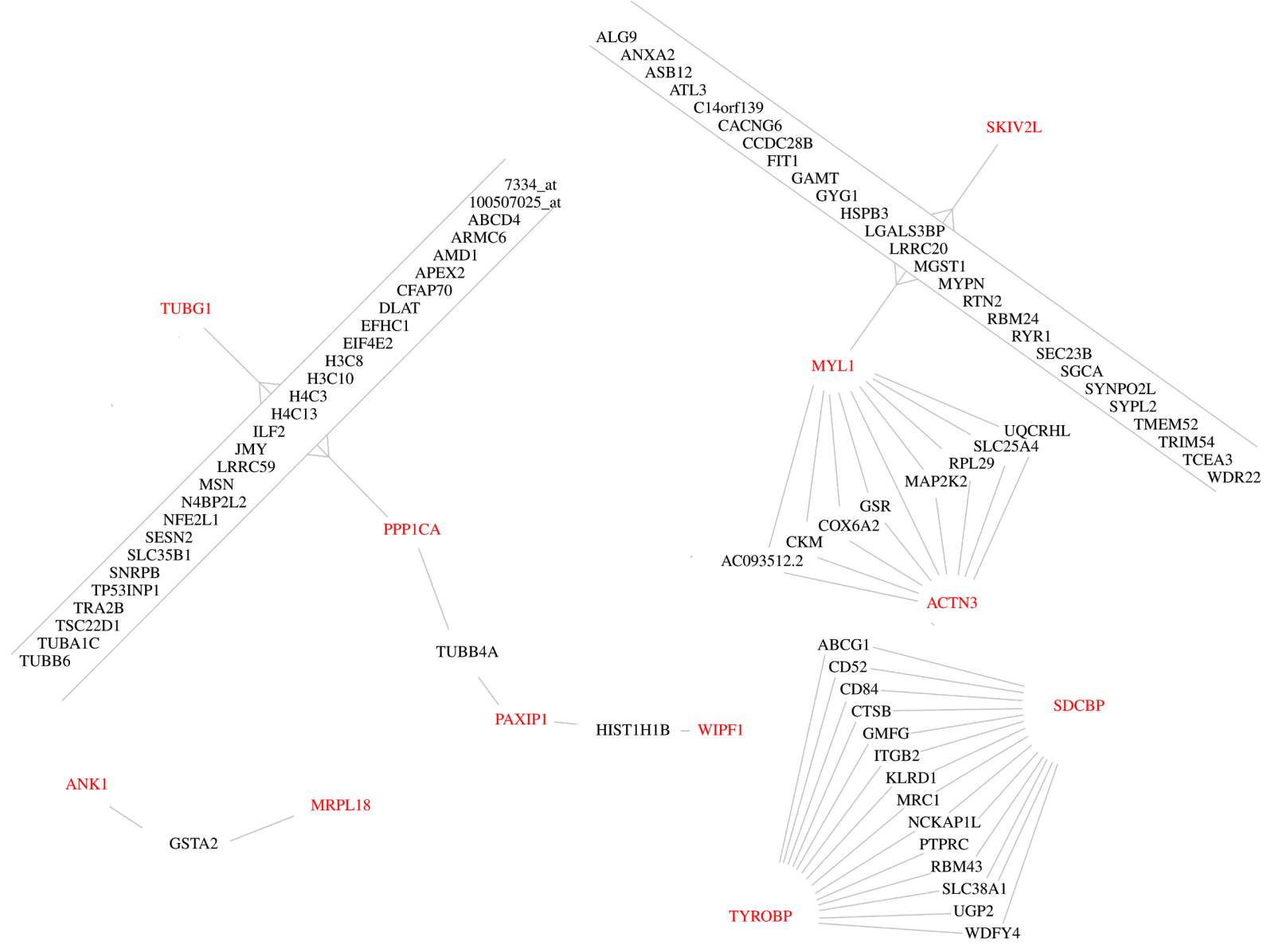

Figure 2: Cross-species conserved hub genes observed in health(span)-associated WGCNA modules, and genes that connect these hub genes. Connections are interactions taken from the WGCNA adjacency matrix if the adjacency is above the $95^{\text {th }}$ percentile of all interactions of that experiment and if for that experiment the interaction is in a health(span)-associated module. The only direct interaction between hub genes is between MYL1 and ACTN3.

To prioritize the cross-species hub genes of Table 2, we also looked at the module membership of all genes for each module. The genes most correlating with the module's eigengene are reported and, analogous to Table 2, the genes that are found in multiple species were determined and listed in Table 3. This table further indicates whether a gene's change in expression is positively or negatively correlated with the eigengene of the WGCNA module to which it belongs, which in turn may be positively or negatively correlated with the health(span) phenotype. Supplement Table 1 shows the raw data that were used to 
construct Table 3. To allow for a direct comparison of the genes' correlation with health(span), not quantitatively but in terms of direction (that is, up- or downregulation in relation to the health phenotype score), Table 3 presents a gene's inverted direction if the gene's module is already negatively correlated with the health(span) phenotype. The "Consensus Correlation" presents the direction that all experiments are in agreement with or "mixed" if the experiments differ in terms of their correlation with the health phenotype score. This information can be calculated for all genes, which we consider to help interpreting a module. For each module, the data for the 30 genes correlating the strongest with the module's eigengene are therefore provided in the supplement (Supplement Table 1).

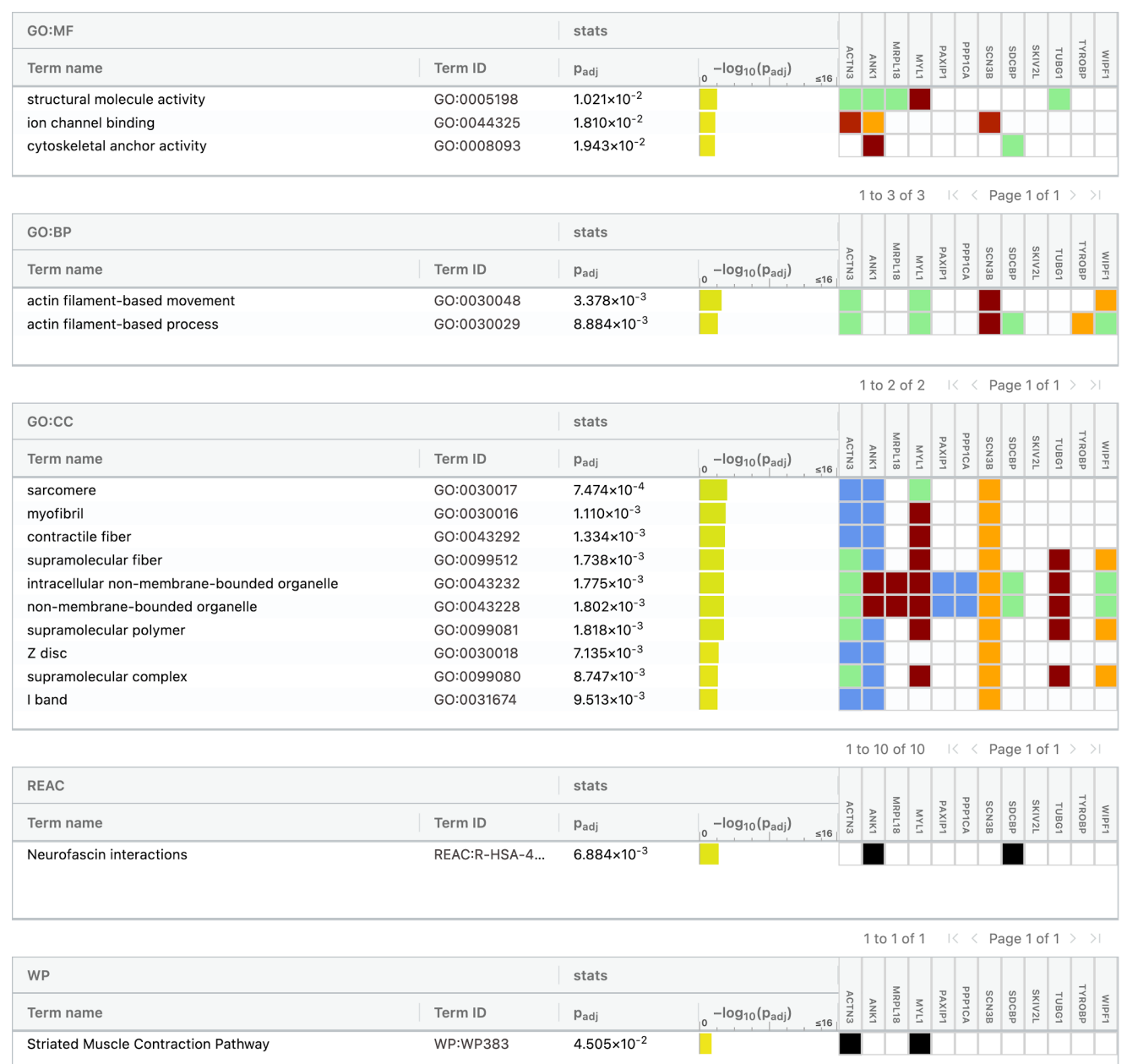

Figure 3: Gene set enrichment analysis of cross-species hub genes for health(span) with g:profiler. Input are genes from Table 2 that are observed in healthspan-associated modules of multiple species. Terms with a low coverage of genes are not suitable to describe the selection as a whole but may still direct the interpretation of parts of the network where these genes are connected.

The intersection of Tables 2 (hub genes) and 3 (genes correlating with the health phenotype score) points to a subset of genes that are considered both influential and directly associated with health, i.e. MYL1, PAXIP1, PPP1CA, SCN3B, TUBG1 and WIPF1. The enrichment by g:profiler for the genes of Table 2 are shown in Figure 3. Supplement Figure 1a shows an enrichment analysis for the intersection of Tables 2 and 3 which is matching closely the enrichments in Figure 3, except that it does not feature the terms associated with muscle. 
Supplement Figure $1 \mathrm{~b}$ shows the enrichment for all genes in Table 3. The latter is the least robust since the enriched terms do not cover a large fraction of the genes as for the other enrichment analyses.

\section{Discussion}

\section{Method}

The onset of this investigation were all experiments in GEO/ArrayExpress that mention "healthspan" in their description (or "health" or "healthspan" in case of worm). For each experiment, from the descriptions that are provided for the samples in the database, a "health phenotype score" was derived. A gene expression correlation analysis with WGCNA yielded a gene coexpression network for each experiment as a set of modules of genes that correlate with the health(span) phenotype. We were interested in genes that are most connected, i.e. hub genes, for each module, and in their interactions as described by the WGCNA network. The correlation of genes with the module eigengene (Table 3), to predict a positive or negative association with health in the molecular context of that module, was only of secondary interest to us.

In this analysis, we focussed on common observations across two or more species and a variety of health-related phenotypes, including the reaction to drugs that extend healthspan (Table 1). The first steps of our analysis with WGCNA identified modules directly from the expression data, i.e. without inspecting a phenotype; the selection of health(span)-associated modules was performed in a later step. The WGCNA protocol was directly derived from the WGCNA tutorial.

The selection of genes, based on strong connectivity, from modules selected in such a way shall hence be considered robust even if the mapping of the multi-factorial sample descriptions to a single factor, that is, the health phenotype score describing the health-effect observed in samples, may allow for plausible alternatives. This is another reason, besides the need for abstraction to compare experiments, why we consider it advantageous to compare the module's genes against the module's eigengene, which is derived solely by an inspection of the expression data, and not against the health phenotype score (as done in Table 3). The manual intervention to derive the health phenotype score was solely needed to filter for health(span) associated modules (Table 3).

To filter for gene interactions, we decided to filter for the strongest $5 \%$ of adjacencies from each experiment, further constrained to modules that are associated with the health(span) phenotype score; see the Methods section for details. This experiment-dependent threshold reflects that experiments differ in the number of samples and subgroups and hence in the contrasts to separate genes by their correlations.

The authors of WGCNA suggested that their software can be used to perform network meta-studies from multiple microarray experiments in a single WGCNA setup (Langfelder et al., 2013). But they clearly stated that the same module needs to be robust across experiments to directly perform WGCNA on a single joint matrix based on all expression data. For the very diverse set of experiments contributing to our analysis and their polygenic phenotype this is not necessarily expected to be the case, i.e. experiments may have their 
true healthspan-associated module in different sections of the transcriptome. Indeed, we did not observe any interactions to have orthologs across species. The setup presented here is pragmatic and robust, i.e. individual experiments can be removed without affecting the gene interactions determined for another experiment. Of major concern for us was that hub genes are expected to show a measurable effect on health(span) only under the conditions of those ArrayExpress/GEO experiments in which they are differentially expressed. To follow this work up with wet lab confirmations, it is hence essential to provide provenance information on how the change to the hub gene's expression was induced, i.e. a pointer to the ArrayExpress/GEO experiment. In a joint matrix across many experiments this information would be more difficult to retrieve, which suggests not to conduct the integration of experiments directly within a single WCGNA analysis.

Furthermore, for integrating interaction data from multiple experiments, the authors of WGCNA suggested to weigh the interactions from each experiment to derive a single joint adjacency matrix and they suggested to apply a threshold on that single matrix to derive a network. Because of the heterogeneity of our experiments, we cannot tell which experiment would be more informative for health(span), compared to another, and thus could not adjust weights accordingly. By treating all experiments individually, and the null hypothesis that all experiments have the same fraction of true interactions that shall be identified by the respective highest adjacency values, we could use an experiment-tailored threshold for filtering the interactions. Therefore, we used the $95^{\text {th }}$ percentile of correlation values in the adjacency matrix, for each experiment, to adapt the selection of the interactions to be forwarded to describe a meta-study consensus (see Figures 1 and 2). These gene interactions may be trusted and they thus could be reassembled into a larger integrated meta-study network to reflect the molecular neighborhoods of hub genes, which we presented as Figure 2 (cross-species) and Supplement Figures 2a-d (for multiple modules of the respective same species). The comparison of findings across species further strengthens the confidence in the WGCNA results. Thus, we identified conserved candidate regulators of health(span).

An important technical concern lies with the interpretation of gene expression correlation data for RNA-seq experiments, which have an intrinsic high noise-level for low-abundant genes. We have recently shown (Struckmann et al., 2020) that even for array data (that are less noisy for low-abundant genes), also the low-abundant genes have a measurable effect on a ranking of genes by Pearson correlation, and this is likely also the case for module calculations as performed here. This concern has to be borne in mind in the following interpretation of the modules in terms of biological functionality.

\section{Cross-species hub genes and their interactions}

Most of the hub genes identified by our analysis (Table 2) have been described in a health(span)-context before. The gene set enrichment analysis with g:profiler describes the molecular roles of the cross-species hub genes (Table 2) as specifically associated with a) features of the muscle and b) actin filament-based organelles and movement (Figure 3). The worm is a model species also for muscle development because of striking similarities of its muscles to mammalian muscle tissue (Christian and Benian, 2020), and movement (locomotion) is an important phenotype in all species towards operationalizing health by 
quantification (Fuellen et al. 2019). For human, rat and mouse in Table 1, there are experiments for which samples were selectively taken from muscle tissue, but not so for the worm, which is routinely sequenced as a whole. Upon closer inspection of the enrichment results of Figure 3, we found that "actin filament-based movement" refers to a wide spectrum of processes, i.e. genes that support actin polymerisation (WIPF1), the motor protein myosin (MYL1) or the transition of endosomes into exosomes for intercellular communication (SDCBP).

The number of experiments of vertebrates and invertebrates is balanced. Apart from a lack of tissue specificity, the experiments for the worm differ from rodents and humans, in that experiments for the worm may comprise samples from different larval stages. This may ease the task to find strong correlations between genes, but specificity for aging-associated processes is likely reduced.

Inspecting the distribution of hub genes by species, we found no more than five of the 12 hub genes in worm, cf. Supplement Figure 2b, and four in human, cf. Supplement Figure 2a. The only conserved direct interaction between consensus hub genes was observed between MYL1 and ACTN3 (Figure 2). However, interactions were found multiple times for experiments of the same species, namely ABRA with VRK2, AQP11 with GSTA2 and CYLD with PCNX2 for the worm. These three interactions are shown in Supplement Figure $2 \mathrm{~b}$ and the VRK2 gene remains directly connected with the PPP1CA hub gene also after the minimum-spanning-tree-based edge removal. VRK2 is described to have downstream effects on the consensus hub gene PPP1CA (Cossa et al., 2020) via GSK3beta (Lee et al.. $\underline{2016}$ ). Its genetic variants are associated with a series of neurological diseases and viral infection, but also with healthspan associated sleep patterns (Dashti et al., 2019). The interactions conserved in multiple species are not confirmed in STRING (Szklarczyk et al.. 2021) for the human, but for the worm, the consensus hub gene PPP1CA (C06A1.3) links to VRK2 (tag-191).

By interpreting the enrichments in Supplement Figure 3 we can gain more insight into how the genes we discovered may be involved in health. An example is the enrichment referring to the TYROBP pathway described in wikipathways and to the GO term Leukocyte activation (Supplement Figure 3a). Genes connecting MYL1 and SKIV2L are involved in muscular structures (Supplement Figure 3b). Tubulins (e.g. TUBG1) are known to bind to PP1, of which PPP1CA is a subunit and together these proteins regulate histone acetylation (Ding et al., 2008), which is reflected by the genes connecting PPP1CA and TUBG1 (Supplement Figure $3 c$ ). Further, enhanced histone acetylation is associated with extended health and lifespan in worm (Zhang et al., 2009).

The highly connected genes selected in this study differ from the list we recently published (Möller et al., 2020). This WGCNA-based study does not refer to prior knowledge about genetic contributions and does not perform a factor analysis to directly associate genes with a health(span) phenotype. Instead, our focus here is the network-centric interpretation of correlations within gene co-expression clusters, i.e. WCGNA modules. It is the module as a whole that correlates in its expression with health, not necessarily the individual genes. Table 3 lists genes within the clusters that are most representative for the features/characteristics of the cluster in question, i.e. that have the highest degree of module membership by 
WGCNA definition, and in the table, there are marks (by boldface) for the subset of genes that are also hub genes. Of the cross-species hub genes in Table 2, six are also listed in Table 3. Others are "near misses", e.g. Table 3 does not list the consensus hub gene MRPL18 but MRPL19. And besides the consensus hub gene PPP1CA, other PP1 subunits like PPP1CB and PPP2R3C are found in two species (Table 3). PPP1CB was also found as a hub gene, but only for the worm.

In Table 3, we report SQSTM1 as the only gene that is associated with health in three species. That gene was long suggested to be aging- and health-related (Bitto et al., 2014; Sánchez-Martín and Komatsu, 2018), also for human, even though it was only found associated in the analyses of the animal experiments in this study. Its transcript is negatively correlated with health, but SQSTM1 overexpression is known to extend healthspan in worm (Kumsta et al., 2019), which may be suggestive for a protective upregulation effect.

Overall, our meta-analysis of a very diverse set of transcriptomics experiments successfully identified genes which, for the most part, were already established to be closely associated with health(span), and together they have a strong and meaningful GO term enrichment. The enrichment of muscle-related genes can be credited to our focus on health(span) experiments, and our study found many "actin filament-based movement" genes (Figure 3) that provide the cellular infrastructure not just for movement, but also for signalling and cell division, which may be triggered/blocked whenever cells start to feel unwell. If so, then it may be possible to detect many healthspan genes solely by inspecting cellular data. This hypothesis may be confirmed by an extension of our setup to a larger set of cellular transcriptomics data sets for which samples vary in their genetic or environmental exposure to stress factors.

This study provided a cross-species meta-study of gene interactions for health(span)-related datasets in ArrayExpress/GEO. It focused on a co-expression network analysis and subsequently on derived hub genes, instead of a focus on those genes that correlate the most with the healthspan phenotype score. This approach shall allow for an abstraction from the experiment at hand and permit a search for common mediators of an effect. The proposed consensus hub genes were plausible in their implication into health(span). Their interactions could be confirmed in STRING, or were found consistent with gene set enrichment analyses and they may support the interpretation of joint or epistatic effects between pairs of haplotypes in healthspan GWAS or linkage analyses. The protocol as provided with WGCNA is very transparent so that findings can be traced back to the experiments that are backing them, to serve as a template for further investigations in the wet lab.

\section{Acknowledgements}

This work was supported by a project from the European Union's Horizon 2020 research and innovation programme under Grant agreement No 633589 (Aging with Elegans), and by the BMBF (Validierung des technologischen und gesellschaftlichen Innovationspotenzials wissenschaftlicher Forschung - VIP+, FKZ: 03VP06230). 


\section{Availability}

Our implementation is available online at https://bitbucket.org/ibima/healthspantranscriptomicsnetworks/.

\section{References}

Adler, Priit, Raivo Kolde, Meelis Kull, Aleksandr

Tkachenko, Hedi Peterson, Jüri Reimand, and Jaak

Vilo. 2009. "Mining for Coexpression across

Hundreds of Datasets Using Novel Rank

Aggregation and Visualization Methods." Genome

Biology 10 (12): R139.

https://doi.org/10.1186/gb-2009-10-12-r139.

Aging Atlas Consortium, Guang-Hui Liu, Yiming Bao, Jing Qu, Weiqi Zhang, Tao Zhang, Wang Kang, et al. 2021. "Aging Atlas: A Multi-Omics Database for Aging Biology." Nucleic Acids Research 49 (D1): D825-30. https://doi.org/10.1093/nar/gkaa894.

Alvarado-Kristensson, Maria. 2018. " $\mathrm{Y}$-Tubulin as a

Signal-Transducing Molecule and Meshwork with

Therapeutic Potential." Signal Transduction and

Targeted Therapy 3 (1): 24.

https://doi.org/10.1038/s41392-018-0021-x.

Amar, David, Hershel Safer, and Ron Shamir. 2013.

"Dissection of Regulatory Networks That Are

Altered in Disease via Differential Co-Expression."

Edited by Donna K. Slonim. PLoS Computational

Biology 9 (3): e1002955.

https://doi.org/10.1371/journal.pcbi.1002955.

Athar, Awais, Anja Füllgrabe, Nancy George, Haider

Iqbal, Laura Huerta, Ahmed Ali, Catherine Snow, et

al. 2019. "ArrayExpress Update - from Bulk to

Single-Cell Expression Data." Nucleic Acids

Research 47 (D1): D711-15.

https://doi.org/10.1093/nar/gky964.

Avelar, Roberto A., Javier Gómez Ortega, Robi

Tacutu, Eleanor J. Tyler, Dominic Bennett, Paolo

Binetti, Arie Budovsky, et al. 2020. "A

Multidimensional Systems Biology Analysis of

Cellular Senescence in Aging and Disease."

Genome Biology 21 (1): 91.

https://doi.org/10.1186/s13059-020-01990-9.

Baietti, Maria Francesca, Zhe Zhang, Eva Mortier,

Aurélie Melchior, Gisèle Degeest, Annelies

Geeraerts, Ylva Ivarsson, et al. 2012.

"Syndecan-Syntenin-ALIX Regulates the Biogenesis of Exosomes." Nature Cell Biology 14 (7): 677-85.

https://doi.org/10.1038/ncb2502.

Banzhaf-Strathmann, Julia, Eva Benito, Stephanie May, Thomas Arzberger, Sabina Tahirovic, Hans Kretzschmar, André Fischer, and Dieter Edbauer. 2014. "Micro RNA - 125b Induces Tau Hyperphosphorylation and Cognitive Deficits in Alzheimer's Disease." The EMBO Journal 33 (15): 1667-80. https://doi.org/10.15252/embj.201387576. Bitto, Alessandro, Chad A. Lerner, Timothy Nacarelli, Elizabeth Crowe, Claudio Torres, and Christian Sell. 2014. "P62/SQSTM1 at the Interface of Aging, Autophagy, and Disease." AGE 36 (3): 9626. https://doi.org/10.1007/s11357-014-9626-3. Blanco, Ignacio, Karoline Kuchenbaecker, Daniel Cuadras, Xianshu Wang, Daniel Barrowdale, Gorka Ruiz de Garibay, Pablo Librado, et al. 2015.

"Assessing Associations between the AURKA-HMMR-TPX2-TUBG1 Functional Module and Breast Cancer Risk in BRCA1/2 Mutation Carriers." PloS One 10 (4): e0120020. https://doi.org/10.1371/journal.pone.0120020.

Brewer, Rachel A., Victoria K. Gibbs, and Daniel L. Smith. 2016. "Targeting Glucose Metabolism for Healthy Aging." Nutrition and Healthy Aging 4 (1): 31-46. https://doi.org/10.3233/NHA-160007. Bushnell, Brian, Jonathan Rood, and Esther Singer. 2017. "BBMerge - Accurate Paired Shotgun Read Merging via Overlap." Edited by Patrick Jon Biggs. PLOS ONE 12 (10): e0185056.

https://doi.org/10.1371/journal.pone.0185056.

Caracciolo, Valentina, Luca D’Agostino, Eduarda

Dráberová, Vladimíra Sládková, Catena

Crozier-Fitzgerald, Dimitri P. Agamanolis, Jean-Pierre de Chadarévian, et al. 2010.

"Differential Expression and Cellular Distribution of Gamma-Tubulin and BetallI-Tubulin in Medulloblastomas and Human Medulloblastoma Cell Lines." Journal of Cellular Physiology 223 (2): 519-29. https://doi.org/10.1002/jcp.22077. 
Castermans, Dries, Ils Somers, Johan Kriel, Wendy Louwet, Stefaan Wera, Matthias Versele, Veerle Janssens, and Johan M Thevelein. 2012.

"Glucose-Induced Posttranslational Activation of Protein Phosphatases PP2A and PP1 in Yeast." Cell Research 22 (6): 1058-77.

https://doi.org/10.1038/cr.2012.20.

Castro, M. E., I. Ferrer, A. Cascon, M. V. Guijarro, M. Lleonart, S. R. y Cajal, J. F.M. Leal, M. Robledo, and A. Carnero. 2007. "PPP1CA Contributes to the Senescence Program Induced by Oncogenic Ras." Carcinogenesis 29 (3): 491-99.

https://doi.org/10.1093/carcin/bgm246.

Ceulemans, Hugo, and Mathieu Bollen. 2004.

"Functional Diversity of Protein Phosphatase-1, a

Cellular Economizer and Reset Button."

Physiological Reviews 84 (1): 1-39.

https://doi.org/10.1152/physrev.00013.2003.

Chen, Di, Patrick Wai-Lun Li, Benjamin A. Goldstein, Waijiao Cai, Emma Lynn Thomas, Fen Chen, Alan E. Hubbard, Simon Melov, and Pankaj Kapahi. 2013. "Germline Signaling Mediates the Synergistically Prolonged Longevity Produced by Double Mutations in Daf-2 and Rsks-1 in C.

Elegans." Cell Reports 5 (6): 1600-1610.

https://doi.org/10.1016/i.celrep.2013.11.018.

Christian, Courtney J., and Guy M. Benian. 2020.

"Animal Models of Sarcopenia." Aging Cell 19 (10).

https://doi.org/10.1111/acel.13223.

Clough, Emily, and Tanya Barrett. 2016. "The Gene

Expression Omnibus Database." In Statistical

Genomics, edited by Ewy Mathé and Sean Davis, 1418:93-110. Methods in Molecular Biology. New York, NY: Springer New York.

https://doi.org/10.1007/978-1-4939-3578-9 5.

Cobley, James, Zulezwan Ab. Malik, James Morton, Graeme Close, Ben Edwards, and Jatin Burniston. 2016. "Age- and Activity-Related Differences in the Abundance of Myosin Essential and Regulatory Light Chains in Human Muscle." Proteomes 4 (2): 15. https://doi.org/10.3390/proteomes4020015.

Cossa, Giacomo, Isabelle Roeschert, Florian Prinz, Apoorva Baluapuri, Raphael Silveira Vidal, Christina Schülein-Völk, Yun-Chien Chang, et al. 2020. "Localized Inhibition of Protein Phosphatase 1 by NUAK1 Promotes Spliceosome Activity and Reveals a MYC-Sensitive Feedback Control of Transcription." Molecular Cell 77 (6): 1322-1339.e11.

https://doi.org/10.1016/j.molcel.2020.01.008.

Cowen, Lenore, Trey Ideker, Benjamin J. Raphael, and Roded Sharan. 2017. "Network Propagation: A Universal Amplifier of Genetic Associations." Nature Reviews Genetics 18 (9): 551-62. https://doi.org/10.1038/nrg.2017.38.

Dam, Sipko van, Rui Cordeiro, Thomas Craig, Jesse van Dam, Shona H Wood, and João de Magalhães. 2012. "GeneFriends: An Online Co-Expression Analysis Tool to Identify Novel Gene Targets for Aging and Complex Diseases." BMC Genomics 13 (1): 535. https://doi.org/10.1186/1471-2164-13-535. Dam, Sipko van, Urmo Võsa, Adriaan van der Graaf, Lude Franke, and João Pedro de Magalhães. 2017. "Gene Co-Expression Analysis for Functional Classification and Gene-Disease Predictions." Briefings in Bioinformatics, January, bbw139. https://doi.org/10.1093/bib/bbw139.

Dashti, Hassan S., Samuel E. Jones, Andrew R. Wood, Jacqueline M. Lane, Vincent T. van Hees, Heming Wang, Jessica A. Rhodes, et al. 2019. "Genome-Wide Association Study Identifies Genetic Loci for Self-Reported Habitual Sleep Duration Supported by Accelerometer-Derived Estimates." Nature Communications 10 (1): 1100. https://doi.org/10.1038/s41467-019-08917-4.

Del Puerto-Nevado, Laura, Aranzazu

Santiago-Hernandez, Sonia Solanes-Casado, Nieves Gonzalez, Marta Ricote, Marta Corton, Isabel Prieto, et al. 2019. "Diabetes-mediated Promotion of Colon Mucosa Carcinogenesis Is Associated with Mitochondrial Dysfunction." Molecular Oncology 13 (9): 1887-97. https://doi.org/10.1002/1878-0261.12531.

Ding, Huiping, Philip J. Dolan, and Gail V. W. Johnson. 2008. "Histone Deacetylase 6 Interacts with the Microtubule-Associated Protein Tau." Journal of Neurochemistry 106 (5): 2119-30. https://doi.org/10.1111/j.1471-4159.2008.05564.x.

Dobin, Alexander, Carrie A. Davis, Felix Schlesinger, Jorg Drenkow, Chris Zaleski, Sonali Jha, Philippe Batut, Mark Chaisson, and Thomas R. Gingeras. 2013. "STAR: Ultrafast Universal RNA-Seq Aligner." Bioinformatics 29 (1): 15-21. https://doi.org/10.1093/bioinformatics/bts635.

Dönertaş, Handan Melike, Matías Fuentealba Valenzuela, Linda Partridge, and Janet M. Thornton. 
2018. "Gene Expression-Based Drug Repurposing to Target Aging." Aging Cell 17 (5): e12819. https://doi.org/10.1111/acel.12819.

Eckard, Sterling C, Gillian I Rice, Alexandre Fabre, Catherine Badens, Elizabeth E Gray, Jane L Hartley, Yanick J Crow, and Daniel B Stetson. 2014. "The SKIV2L RNA Exosome Limits Activation of the RIG-I-like Receptors." Nature Immunology 15 (9): 839-45. https://doi.org/10.1038/ni.2948.

Fares, Joanna, Rudra Kashyap, and Pascale Zimmermann. 2017. "Syntenin: Key Player in Cancer Exosome Biogenesis and Uptake?" Cell Adhesion \& Migration 11 (2): 124-26. https://doi.org/10.1080/19336918.2016.1225632.

Finley, L. W. S., J. Lee, A. Souza, V.

Desquiret-Dumas, K. Bullock, G. C. Rowe, V. Procaccio, C. B. Clish, Z. Arany, and M. C. Haigis. 2012. "Skeletal Muscle Transcriptional Coactivator PGC-1 Mediates Mitochondrial, but Not Metabolic, Changes during Calorie Restriction." Proceedings of the National Academy of Sciences 109 (8):

2931-36. https://doi.org/10.1073/pnas.1115813109.

Franz, Max, Harold Rodriguez, Christian Lopes, Khalid Zuberi, Jason Montojo, Gary D Bader, and Quaid Morris. 2018. "GeneMANIA Update 2018." Nucleic Acids Research 46 (W1): W60-64. https://doi.org/10.1093/nar/gky311.

Fuellen, Georg, Ludger Jansen, Alan A Cohen, Walter Luyten, Manfred Gogol, Andreas Simm, Nadine Saul, et al. 2019. "Health and Aging: Unifying Concepts, Scores, Biomarkers and Pathways." Aging and Disease 10 (4): 883. https://doi.org/10.14336/AD.2018.1030.

Greer, Eric L., Travis J. Maures, Anna G. Hauswirth, Erin M. Green, Dena S. Leeman, Géraldine S. Maro, Shuo Han, Max R. Banko, Or Gozani, and Anne Brunet. 2010. "Members of the H3K4 Trimethylation Complex Regulate Lifespan in a Germline-Dependent Manner in C. Elegans." Nature 466 (7304): 383-87.

https://doi.org/10.1038/nature09195.

Harvey, Simon C, Gary LA Barker, Alison Shorto, and Mark E Viney. 2009a. "Natural Variation in Gene Expression in the Early Development of Dauer Larvae of Caenorhabditis Elegans." BMC Genomics 10 (1): 325.

https://doi.org/10.1186/1471-2164-10-325.
Herrera-Moyano, Emilia, Rosa Maria Porreca, Lepakshi Ranjha, Roser Gonzalez-Franco, Eleni Skourti, Ying Sun, Emmanouil Stylianakis, Alex Montoya, Holger Kramer, and Jean-Baptiste Vannier. 2020. "Human SKI Is a

Telomere-Associated Complex Involved in DNA-RNA Hybrid Control and Telomere Stability." Preprint. Molecular Biology. https://doi.org/10.1101/2020.05.20.107144. Ideker, Trey, Janusz Dutkowski, and Leroy Hood. 2011. "Boosting Signal-to-Noise in Complex Biology: Prior Knowledge Is Power." Cell 144 (6): 860-63. https://doi.org/10.1016/j.cell.2011.03.007. Ishikawa, Taisuke, Naohiko Takahashi, Seiko Ohno, Harumizu Sakurada, Kazufumi Nakamura, Young Keun On, Jeong Euy Park, et al. 2013. "Novel SCN3B Mutation Associated with Brugada Syndrome Affects Intracellular Trafficking and Function of Nav1.5." Circulation Journal: Official Journal of the Japanese Circulation Society 77 (4): 959-67. https://doi.org/10.1253/circj.cj-12-0995. Jackson, Belinda M., Patricia Abete-Luzi, Michael W. Krause, and David M. Eisenmann. 2014. "Use of an Activated Beta-Catenin to Identify Wnt Pathway Target Genes in Caenorhabditis Elegans , Including a Subset of Collagen Genes Expressed in Late Larval Development." G3\&amp;\#58; Genes|Genomes|Genetics 4 (4): 733-47. https://doi.org/10.1534/g3.113.009522.

Jiang, Junjie, Yongfeng Ding, Mengjie Wu, Xiadong Lyu, Haifeng Wang, Yanyan Chen, Haiyong Wang, and Lisong Teng. 2020. "Identification of TYROBP and C1QB as Two Novel Key Genes With Prognostic Value in Gastric Cancer by Network Analysis." Frontiers in Oncology 10 (September): 1765. https://doi.org/10.3389/fonc.2020.01765.

Kim, Yeo Jin, Hyun Soo Kim, and Young Rok Seo. 2018. "Genomic Approach to Understand the Association of DNA Repair with Longevity and Healthy Aging Using Genomic Databases of Oldest-Old Population." Oxidative Medicine and Cellular Longevity 2018: 1-12. https://doi.org/10.1155/2018/2984730.

Korrodi-Gregório, Luís, Joana Vieira Silva, Luís Santos-Sousa, Maria João Freitas, Juliana Felgueiras, and Margarida Fardilha. 2014. "TGF- $\beta$ Cascade Regulation by PPP1 and Its Interactors -Impact on Prostate Cancer Development and 
Therapy." Journal of Cellular and Molecular

Medicine 18 (4): 555-67.

https://doi.org/10.1111/jcmm.12266.

Kotlyar, Max, Chiara Pastrello, Zara Malik, and Igor Jurisica. 2019. "IID 2018 Update: Context-Specific Physical Protein-Protein Interactions in Human, Model Organisms and Domesticated Species." Nucleic Acids Research 47 (D1): D581-89. https://doi.org/10.1093/nar/gky1037.

Kucera, Mike, Ruth Isserlin, Arkady Arkhangorodsky, and Gary D. Bader. 2016. "AutoAnnotate: A Cytoscape App for Summarizing Networks with Semantic Annotations." F1000Research 5 (July): 1717.

https://doi.org/10.12688/f1000research.9090.1. Kumsta, Caroline, Jessica T. Chang, Reina Lee, Ee Phie Tan, Yongzhi Yang, Rute Loureiro, Elizabeth $\mathrm{H}$. Choy, et al. 2019. "The Autophagy Receptor P62/SQST-1 Promotes Proteostasis and Longevity in C. Elegans by Inducing Autophagy." Nature Communications 10 (1): 5648. https://doi.org/10.1038/s41467-019-13540-4.

Langfelder, Peter, and Steve Horvath. 2008. "WGCNA: An R Package for Weighted Correlation Network Analysis." BMC Bioinformatics 9 (1): 559. https://doi.org/10.1186/1471-2105-9-559.

Langfelder, Peter, Paul S. Mischel, and Steve Horvath. 2013. "When Is Hub Gene Selection Better than Standard Meta-Analysis?" Edited by Timothy Ravasi. PLoS ONE 8 (4): e61505.

https://doi.org/10.1371/journal.pone.0061505.

Lee, Eunju, Hye Guk Ryu, Sangjune Kim, Dohyun Lee, Young-Hun Jeong, and Kyong-Tai Kim. 2016. "Glycogen Synthase Kinase $3 \beta$ Suppresses Polyglutamine Aggregation by Inhibiting Vaccinia-Related Kinase 2 Activity." Scientific Reports 6 (1): 29097.

https://doi.org/10.1038/srep29097.

Lee, John, Manthan Shah, Sara Ballouz, Megan Crow, and Jesse Gillis. 2020. "CoCoCoNet: Conserved and Comparative Co-Expression across a Diverse Set of Species." Nucleic Acids Research 48 (W1): W566-71.

https://doi.org/10.1093/nar/gkaa348.

Lehrbach, N. J., C. Castro, K. J. Murfitt, C. Abreu-Goodger, J. L. Griffin, and E. A. Miska. 2012. "Post-Developmental MicroRNA Expression Is Required for Normal Physiology, and Regulates
Aging in Parallel to Insulin/IGF-1 Signaling in C.

Elegans." RNA 18 (12): 2220-35.

https://doi.org/10.1261/rna.035402.112.

Leinonen, R., R. Akhtar, E. Birney, L. Bower, A.

Cerdeno-Tarraga, Y. Cheng, I. Cleland, et al. 2011.

"The European Nucleotide Archive." Nucleic Acids

Research 39 (Database): D28-31.

https://doi.org/10.1093/nar/gkq967.

Leiserson, Mark DM, Jonathan V Eldridge, Sohini

Ramachandran, and Benjamin J Raphael. 2013.

"Network Analysis of GWAS Data." Current Opinion

in Genetics \& Development 23 (6): 602-10.

https://doi.org/10.1016/j.gde.2013.09.003.

Li, Bo, Victor Ruotti, Ron M. Stewart, James A.

Thomson, and Colin N. Dewey. 2010. "RNA-Seq

Gene Expression Estimation with Read Mapping

Uncertainty." Bioinformatics 26 (4): 493-500.

https://doi.org/10.1093/bioinformatics/btp692.

Li, Ming-Li, Shi-Hao Wu, Jin-Jin Zhang, Hang-Yu Tian, Yong Shao, Zheng-Bo Wang, David M. Irwin, Jia-Li Li, Xin-Tian Hu, and Dong-Dong Wu. 2019. "547 Transcriptomes from 44 Brain Areas Reveal Features of the Aging Brain in Non-Human Primates." Genome Biology 20 (1): 258. https://doi.org/10.1186/s13059-019-1866-1.

Li, Shuai, Jiadi Han, Guili Guo, Yudi Sun, Tingting Zhang, Mingyi Zhao, Yijia Xu, Yong Cui, Yanfeng Liu, and Jinghai Zhang. 2020. "Voltage-Gated Sodium Channels B3 Subunit Promotes Tumorigenesis in Hepatocellular Carcinoma by Facilitating P53 Degradation." FEBS Letters 594 (3): 497-508. https://doi.org/10.1002/1873-3468.13641. Liang, Yaru, and Zhao Wang. 2018. "Which Is the Most Reasonable Anti-Aging Strategy: Meta-Analysis." In Aging and Aging-Related Diseases, edited by Zhao Wang, 1086:267-82. Advances in Experimental Medicine and Biology. Singapore: Springer Singapore. https://doi.org/10.1007/978-981-13-1117-8 17. Liu, Haiying, Yiding Yang, Yuanlong Ge, Juanhong Liu, and Yong Zhao. 2019. "TERC Promotes Cellular Inflammatory Response Independent of Telomerase." Nucleic Acids Research 47 (15): 8084-95. https://doi.org/10.1093/nar/gkz584.

Ma, Jing, Teng Jiang, Lan Tan, and Jin-Tai Yu. 2015. "TYROBP in Alzheimer's Disease." Molecular Neurobiology 51 (2): 820-26. https://doi.org/10.1007/s12035-014-8811-9. 
Magalhães, João Pedro de, João Curado, and George M. Church. 2009. "Meta-Analysis of Age-Related Gene Expression Profiles Identifies Common Signatures of Aging." Bioinformatics 25 (7): 875-81.

https://doi.org/10.1093/bioinformatics/btp073.

Magger, Oded, Yedael Y. Waldman, Eytan Ruppin, and Roded Sharan. 2012. "Enhancing the Prioritization of Disease-Causing Genes through Tissue Specific Protein Interaction Networks." Edited by Donna K. Slonim. PLoS Computational Biology 8 (9): e1002690.

https://doi.org/10.1371/journal.pcbi.1002690.

Manole, Andreea, Stephanie Efthymiou, Emer O'Connor, Marisa I. Mendes, Matthew Jennings, Reza Maroofian, Indran Davagnanam, et al. 2020. "De Novo and Bi-Allelic Pathogenic Variants in NARS1 Cause Neurodevelopmental Delay Due to Toxic Gain-of-Function and Partial Loss-of-Function Effects." The American Journal of Human Genetics 107 (2): 311-24.

https://doi.org/10.1016/j.aihg.2020.06.016.

Maounis, Nicoletta F., Eduarda Dráberová, Eleni Mahera, Maria Chorti, Valentina Caracciolo, Tetyana Sulimenko, Dimitra Riga, et al. 2012. "Overexpression of $\mathrm{Y}$-Tubulin in Non-Small Cell Lung Cancer." Histology and Histopathology 27 (9): 1183-94. https://doi.org/10.14670/HH-27.1183.

Mercken, Evi M., Seth D. Crosby, Dudley W. Lamming, Lellean JeBailey, Susan Krzysik-Walker, Dennis T. Villareal, Miriam Capri, et al. 2013. "Calorie Restriction in Humans Inhibits the PI3K/AKT Pathway and Induces a Younger Transcription Profile." Aging Cell 12 (4): 645-51. https://doi.org/10.1111/acel.12088.

Mercken, Evi M., Sarah J. Mitchell, Alejandro Martin-Montalvo, Robin K. Minor, Maria Almeida, Ana P. Gomes, Morten Scheibye-Knudsen, et al. 2014. "SRT2104 Extends Survival of Male Mice on a Standard Diet and Preserves Bone and Muscle Mass." Aging Cell 13 (5): 787-96. https://doi.org/10.1111/acel.12220.

Möller, Steffen, Nadine Saul, Alan A. Cohen, Rüdiger Köhling, Sina Sender, Hugo Murua Escobar, Christian Junghanss, et al. 2020. "Healthspan Pathway Maps in C. Elegans and Humans Highlight Transcription, Proliferation/Biosynthesis and Lipids."
Aging 12 (13): 12534-81.

https://doi.org/10.18632/aging.103514.

Morris, Gerwyn, Michael Berk, Michael Maes, and Basant K. Puri. 2019. "Could Alzheimer's Disease Originate in the Periphery and If So How So?" Molecular Neurobiology 56 (1): 406-34. https://doi.org/10.1007/s12035-018-1092-y. Obayashi, Takeshi, Yuki Kagaya, Yuichi Aoki, Shu Tadaka, and Kengo Kinoshita. 2019. "COXPRESdb v7: A Gene Coexpression Database for 11 Animal Species Supported by 23 Coexpression Platforms for Technical Evaluation and Evolutionary Inference." Nucleic Acids Research 47 (D1): D55-62. https://doi.org/10.1093/nar/gky1155. Pan, Yu, Fengchun Lu, Ping Xiong, Maoen Pan, Zheyang Zhang, Xianchao Lin, Minggui Pan, and Heguang Huang. 2018. "WIPF1 Antagonizes the Tumor Suppressive Effect of MiR-141/200c and Is Associated with Poor Survival in Patients with PDAC." Journal of Experimental \& Clinical Cancer Research 37 (1): 167. https://doi.org/10.1186/s13046-018-0848-6.

Pickering, Craig, and John Kiely. 2018. "ACTN3, Morbidity, and Healthy Aging." Frontiers in Genetics 9 (January): 15.

https://doi.org/10.3389/fgene.2018.00015.

Pottier, Cyril, Thomas A. Ravenscroft, Patricia H. Brown, NiCole A. Finch, Matt Baker, Meeia Parsons, Yan W. Asmann, et al. 2016. "TYROBP Genetic Variants in Early-Onset Alzheimer's Disease." Neurobiology of Aging 48 (December): 222.e9-222.e15.

https://doi.org/10.1016/j.neurobiolaging.2016.07.02. Pujol, Nathalie, Olivier Zugasti, Daniel Wong, Carole Couillault, C. Léopold Kurz, Hinrich Schulenburg, and Jonathan J. Ewbank. 2008. "Anti-Fungal Innate Immunity in C. Elegans Is Enhanced by Evolutionary Diversification of Antimicrobial Peptides." Edited by Frederick M. Ausubel. PLoS Pathogens 4 (7): e1000105. https://doi.org/10.1371/journal.ppat.1000105.

Qin, Li, Yanbo Nie, Hong Zhang, Long Chen, Donglei Zhang, Yani Lin, and Kun Ru. 2020. "Identification of New Mutations in Patients with Hereditary Spherocytosis by Next-Generation Sequencing." Journal of Human Genetics 65 (4): 427-34. https://doi.org/10.1038/s10038-020-0724-z. 
Rajagopal, Abbhirami, Anita U. Rao, Julio Amigo, Meng Tian, Sanjeev K. Upadhyay, Caitlin Hall, Suji Uhm, et al. 2008. "Haem Homeostasis Is Regulated by the Conserved and Concerted Functions of HRG-1 Proteins." Nature 453 (7198): 1127-31. https://doi.org/10.1038/nature06934.

Rajesh, Sundaresan, Ružica Bago, Elena Odintsova, Gayrat Muratov, Gouri Baldwin, Pooja Sridhar, Sandya Rajesh, Michael Overduin, and Fedor Berditchevski. 2011. "Binding to Syntenin-1 Protein Defines a New Mode of Ubiquitin-Based Interactions Regulated by Phosphorylation." The Journal of Biological Chemistry 286 (45): 39606-14. https://doi.org/10.1074/jbc.M111.262402.

Ruiz, Lidia, Magali Traskine, Irene Ferrer, Estrella Castro, Juan F. M. Leal, Marcelline Kaufman, and Amancio Carnero. 2008. "Characterization of the P53 Response to Oncogene-Induced Senescence." Edited by Mikhail V. Blagosklonny. PLoS ONE 3 (9): e3230.

https://doi.org/10.1371/journal.pone.0003230.

Sánchez-Martín, Pablo, and Masaaki Komatsu. 2018. "P62/SQSTM1 - Steering the Cell through Health and Disease." Journal of Cell Science 131 (21): jcs222836. https://doi.org/10.1242/jcs.222836.

Schmeisser, Sebastian, Steffen Priebe, Marco Groth, Shamci Monajembashi, Peter Hemmerich, Reinhard Guthke, Matthias Platzer, and Michael Ristow. 2013. "Neuronal ROS Signaling Rather than AMPK/Sirtuin-Mediated Energy Sensing Links Dietary Restriction to Lifespan Extension." Molecular Metabolism 2 (2): 92-102.

https://doi.org/10.1016/j.molmet.2013.02.002.

Schott, Geraldine, and Mariano A. Garcia-Blanco. 2020. "MHC Class III RNA Binding Proteins and Immunity." RNA Biology, December, 1-7. https://doi.org/10.1080/15476286.2020.1860388.

Shuai, Ping, Zimeng Ye, Yuping Liu, Chao Qu, Xiaoqi Liu, Huaichao Luo, Xiaoyun Feng, Xiulan Li, Yi Shi, and Bo Gong. 2017. "Association between SKIV2L Polymorphism Rs429608 and Age-Related Macular Degeneration: A Meta-Analysis." Ophthalmic Genetics 38 (3): 245-51. https://doi.org/10.1080/13816810.2016.1210650.

Silva, Joana V., Maria J. Freitas, and Margarida Fardilha. 2014. "Phosphoprotein Phosphatase 1 Complexes in Spermatogenesis." Current Molecular Pharmacology 7 (2): 136-46. https://doi.org/10.2174/18744672086661501261542 22.

Spracklen, Cassandra N., Momoko Horikoshi, Young Jin Kim, Kuang Lin, Fiona Bragg, Sanghoon Moon, Ken Suzuki, et al. 2020. "Identification of Type 2 Diabetes Loci in 433,540 East Asian Individuals." Nature 582 (7811): 240-45. https://doi.org/10.1038/s41586-020-2263-3. Staub, Eike, Joern Groene, Maya Heinze, Detlev Mennerich, Stefan Roepcke, Irina Klaman, Bernd Hinzmann, et al. 2009. "An Expression Module of WIPF1-Coexpressed Genes Identifies Patients with Favorable Prognosis in Three Tumor Types." Journal of Molecular Medicine 87 (6): 633-44. https://doi.org/10.1007/s00109-009-0467-y. Stranahan, Alexis M., Bronwen Martin, Wayne Chadwick, Sung-Soo Park, Liyun Wang, Kevin G. Becker, William H. Woodiii, Yongqing Zhang, and Stuart Maudsley. 2012. "Metabolic Context Regulates Distinct Hypothalamic Transcriptional Responses to Antiaging Interventions." International Journal of Endocrinology 2012: 732975. https://doi.org/10.1155/2012/732975.

Struckmann, Stephan, Mathias Ernst, Sarah Fischer, Nancy Mah, Georg Fuellen, and Steffen Möller. 2020. "Scoring Functions for Drug-Effect Similarity." Briefings in Bioinformatics, June, bbaa072. https://doi.org/10.1093/bib/bbaa072.

Stuart, Charles A., William L. Stone, Mary E. A. Howell, Marianne F. Brannon, H. Kenton Hall, Andrew L. Gibson, and Michael H. Stone. 2016. "Myosin Content of Individual Human Muscle Fibers Isolated by Laser Capture Microdissection." American Journal of Physiology-Cell Physiology 310 (5): C381-89. https://doi.org/10.1152/ajpcell.00317.2015.

Sun, Hongze, Baochi Ou, Senlin Zhao, Xueni Liu, Liwei Song, Xisheng Liu, Rangrang Wang, and Zhihai Peng. 2019. "USP11 Promotes Growth and Metastasis of Colorectal Cancer via PPP1CA-Mediated Activation of ERK/MAPK Signaling Pathway." EBioMedicine 48 (October): 236-47.

https://doi.org/10.1016/i.ebiom.2019.08.061.

Szklarczyk, Damian, Annika L. Gable, Katerina C. Nastou, David Lyon, Rebecca Kirsch, Sampo Pyysalo, Nadezhda T. Doncheva, et al. 2021. "The STRING Database in 2021: Customizable 
Protein-Protein Networks, and Functional

Characterization of User-Uploaded

Gene/Measurement Sets." Nucleic Acids Research

49 (D1): D605-12.

https://doi.org/10.1093/nar/gkaa1074.

Tacutu, Robi, Thomas Craig, Arie Budovsky, Daniel Wuttke, Gilad Lehmann, Dmitri Taranukha, Joana Costa, Vadim E. Fraifeld, and João Pedro de Magalhães. 2012. "Human Ageing Genomic Resources: Integrated Databases and Tools for the Biology and Genetics of Ageing." Nucleic Acids Research 41 (D1): D1027-33. https://doi.org/10.1093/nar/gks1155.

Tacutu, Robi, Daniel Thornton, Emily Johnson, Arie Budovsky, Diogo Barardo, Thomas Craig, Eugene Diana, et al. 2018. "Human Ageing Genomic Resources: New and Updated Databases." Nucleic Acids Research 46 (D1): D1083-90. https://doi.org/10.1093/nar/gkx1042. van Dam, Sipko, Thomas Craig, and João Pedro de Magalhães. 2015. "GeneFriends: A Human RNA-Seq-Based Gene and Transcript Co-Expression Database." Nucleic Acids Research 43 (D1): D1124-32.

https://doi.org/10.1093/nar/gku1042.

Vardi, Iddo, Ortal Barel, Michal Sperber, Michael Schvimer, Moran Nunberg, Michael Field, Jodie Ouahed, et al. 2018. "Genetic and Structural Analysis of a SKIV2L Mutation Causing Tricho-Hepato-Enteric Syndrome." Digestive Diseases and Sciences 63 (5): 1192-99. https://doi.org/10.1007/s10620-018-4983-x. Visvikis, Orane, Nnamdi Ihuegbu, Sid A. Labed, Lyly G. Luhachack, Anna-Maria F. Alves, Amanda C. Wollenberg, Lynda M. Stuart, Gary D. Stormo, and Javier E. Irazoqui. 2014. "Innate Host Defense Requires TFEB-Mediated Transcription of Cytoprotective and Antimicrobial Genes." Immunity 40 (6): 896-909.

https://doi.org/10.1016/j.immuni.2014.05.002.

Wang, Lu, Zhen Li, David Sievert, Desirée E. C. Smith, Marisa I. Mendes, Dillon Y. Chen, Valentina Stanley, et al. 2020. "Loss of NARS1 Impairs Progenitor Proliferation in Cortical Brain Organoids and Leads to Microcephaly." Nature Communications 11 (1): 4038. https://doi.org/10.1038/s41467-020-17454-4.
Waters, Katherine, Alison Z. Yang, and Valerie Reinke. 2010. "Genome-Wide Analysis of Germ Cell Proliferation in C. Elegans Identifies VRK-1 as a Key Regulator of CEP-1/P53." Developmental Biology 344 (2): 1011-25. https://doi.org/10.1016/j.ydbio.2010.06.022. Wu, Ping, Tingting Xiang, Jing Wang, Run Lv, and Guangzhen Wu. 2020. "TYROBP Is a Potential Prognostic Biomarker of Clear Cell Renal Cell Carcinoma." FEBS Open Bio 10 (12): 2588-2604. https://doi.org/10.1002/2211-5463.12993.

Yang, H., Y. Zhang, J. Vallandingham, H. Li, L. Florens, and H. Y. Mak. 2012. "The RDE-10/RDE-11 Complex Triggers RNAi-Induced MRNA Degradation by Association with Target MRNA in C Elegans." Genes \& Development 26 (8): 846-56. https://doi.org/10.1101/gad.180679.111.

Yates, Andrew D, Premanand Achuthan, Wasiu Akanni, James Allen, Jamie Allen, Jorge Alvarez-Jarreta, M Ridwan Amode, et al. 2019. "Ensembl 2020." Nucleic Acids Research, November, gkz966. https://doi.org/10.1093/nar/gkz966.

Zahn, Jacob M, Suresh Poosala, Art B Owen, Donald $\mathrm{K}$ Ingram, Ana Lustig, Arnell Carter, Ashani T Weeraratna, et al. 2007. "AGEMAP: A Gene Expression Database for Aging in Mice." Edited by Wayne N Frankel. PLoS Genetics 3 (11): e201. https://doi.org/10.1371/journal.pgen.0030201.

Zhang, Minhua, Michal Poplawski, Kelvin Yen, Hui Cheng, Erik Bloss, Xiao Zhu, Harshil Patel, and Charles V. Mobbs. 2009. "Role of CBP and SATB-1 in Aging, Dietary Restriction, and Insulin-Like Signaling." Edited by Andy Dillin. PLoS Biology 7 (11): e1000245. https://doi.org/10.1371/journal.pbio.1000245.

Zhang, Tao, Xiaopei Shen, Rengyun Liu, Guangwu Zhu, Justin Bishop, and Mingzhao Xing. 2017. "Epigenetically Upregulated WIPF1 Plays a Major Role in BRAF V600E-Promoted Papillary Thyroid Cancer Aggressiveness." Oncotarget 8 (1): 900-914.

https://doi.org/10.18632/oncotarget.13400.

Zhang, Xingqian, Xiangwei Gao, Ryan Alex Coots, Crystal S Conn, Botao Liu, and Shu-Bing Qian. 2015. "Translational Control of the Cytosolic Stress Response by Mitochondrial Ribosomal Protein L18." 
bioRxiv preprint doi: https://doi.org/10.1101/2021.04.08.439030; this version posted April 10, 2021. The copyright holder for this preprint (which was not certified by peer review) is the author/funder, who has granted bioRxiv a license to display the preprint in perpetuity. It is made available under aCC-BY 4.0 International license.

Nature Structural \& Molecular Biology 22 (5):

404-10. https://doi.org/10.1038/nsmb.3010.

Zhao, Wei, Peter Langfelder, Tova Fuller, Jun Dong,

Ai Li, and Steve Hovarth. 2010. "Weighted Gene

Coexpression Network Analysis: State of the Art."
Journal of Biopharmaceutical Statistics 20 (2):

281-300.

https://doi.org/10.1080/10543400903572753. 
bioRxiv preprint doi: https://doi.org/10.1101/2021.04.08.439030; this version posted April 10, 2021. The copyright holder for this preprint (which was not certified by peer review) is the author/funder, who has granted bioRxiv a license to display the preprint in perpetuity. It is made available under aCC-BY 4.0 International license.

\section{Supplement}

Figures

\begin{tabular}{|c|c|c|c|c|c|c|c|c|c|c|}
\hline$G O: B P$ & & stats & & & & & & & & \\
\hline Term name & Term ID & $P_{\text {adj }}$ & $0^{-\log _{10}\left(p_{\text {adj }}\right)}$ & $\$ 16$ & & 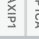 & $\stackrel{0}{\vec{D}}$ & 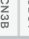 & & 害 \\
\hline actin filament-based movement & GO:0030048 & $1.235 \times 10^{-2}$ & & & & & & & & \\
\hline & & & 1 to 1 of 1 & k & & ge 1 & 1 of 1 & & $>1$ & \\
\hline $\mathrm{GO}: \mathrm{CC}$ & & stats & & & & & & & & \\
\hline Term name & Term ID & $p_{\text {adj }}$ & $0^{-\log _{10}\left(p_{\text {adj }}\right)}$ & $\leq 16$ & s & $\frac{\frac{\pi}{y}}{3}$ & $\frac{0}{3}$ & 第 & & $\frac{2}{3}$ \\
\hline supramolecular fiber & GO:0099512 & $1.709 \times 10^{-2}$ & & & & & & & & \\
\hline supramolecular polymer & GO:0099081 & $1.763 \times 10^{-2}$ & & & & & & & & \\
\hline intracellular non-membrane-bounded organelle & GO:0043232 & $2.217 \times 10^{-2}$ & t. & & & & & & & \\
\hline non-membrane-bounded organelle & GO:0043228 & $2.239 \times 10^{-2}$ & ( & & & & & & & \\
\hline
\end{tabular}

Supplement Figure 1a: g:profiler gene set enrichment analysis of genes listed jointly in Tables 2 and 3.

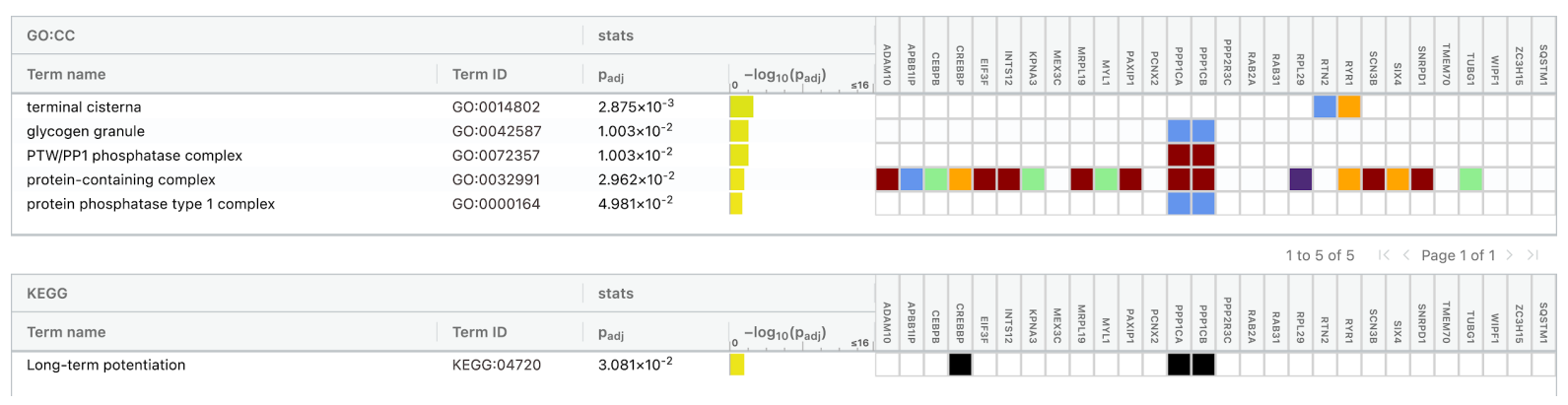

Supplement Figure 1b: g:profiler gene set enrichment analysis of genes listed in Table 3. 


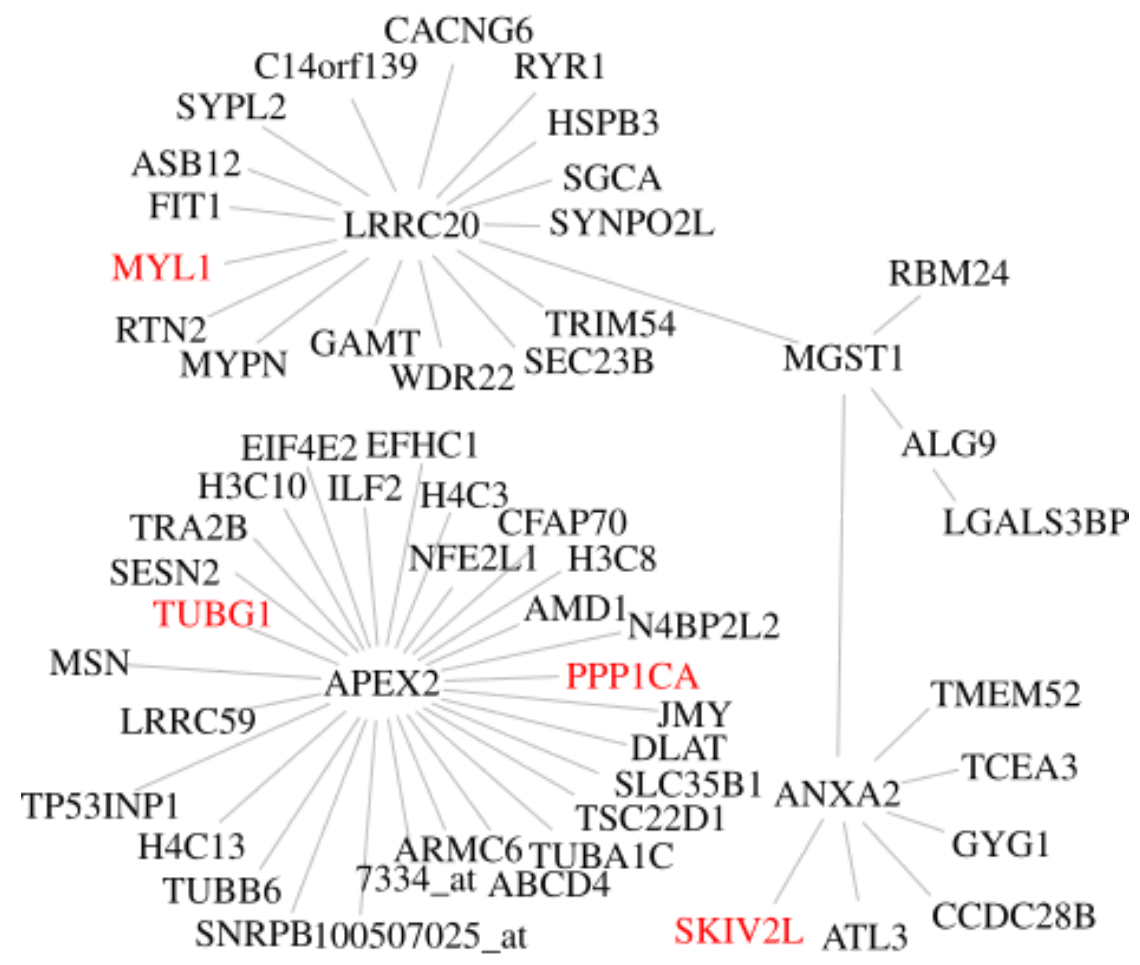

Supplement Figure 2a: Gene interactions observed in human. The genes MYL1, PPP1CA, SKIV2L and TUBG1 are hub genes in WGCNA-defined modules from multiple species (cf. Figure 1, here shown in red). This graph was created iteratively with the red genes as a seed, then adding all the gene-gene interactions from WGCNA in human experiments originating from these red genes, and then transitively adding all the interacting genes of those. The resulting graph is highly interconnected before applying the minimum spanning tree algorithm. The genes interacting with hub genes across species (in red) then appear marginalized by the three human-only hub genes ANXA2, APEX2, LRRC20 and MGST1, given that the minimum spanning tree shows only the strongest correlations. ANXA2 is well described for a wide array of disease, i.e. cancer but also pulmonary fibrosis, and on a molecular level chimes in with vesicle fusion. APEX2 is a nuclease required for lymphocyte proliferation. LRRC20 is not yet described but known to interact with the also mostly undescribed TOM1 that once more is thought to be involved in intracellular trafficking and the E3 SUMO-protein ligase ZBED1. MGST1 is an enzyme located at the ER and mitochondria, a transferase of glutathione, an antioxidant. 


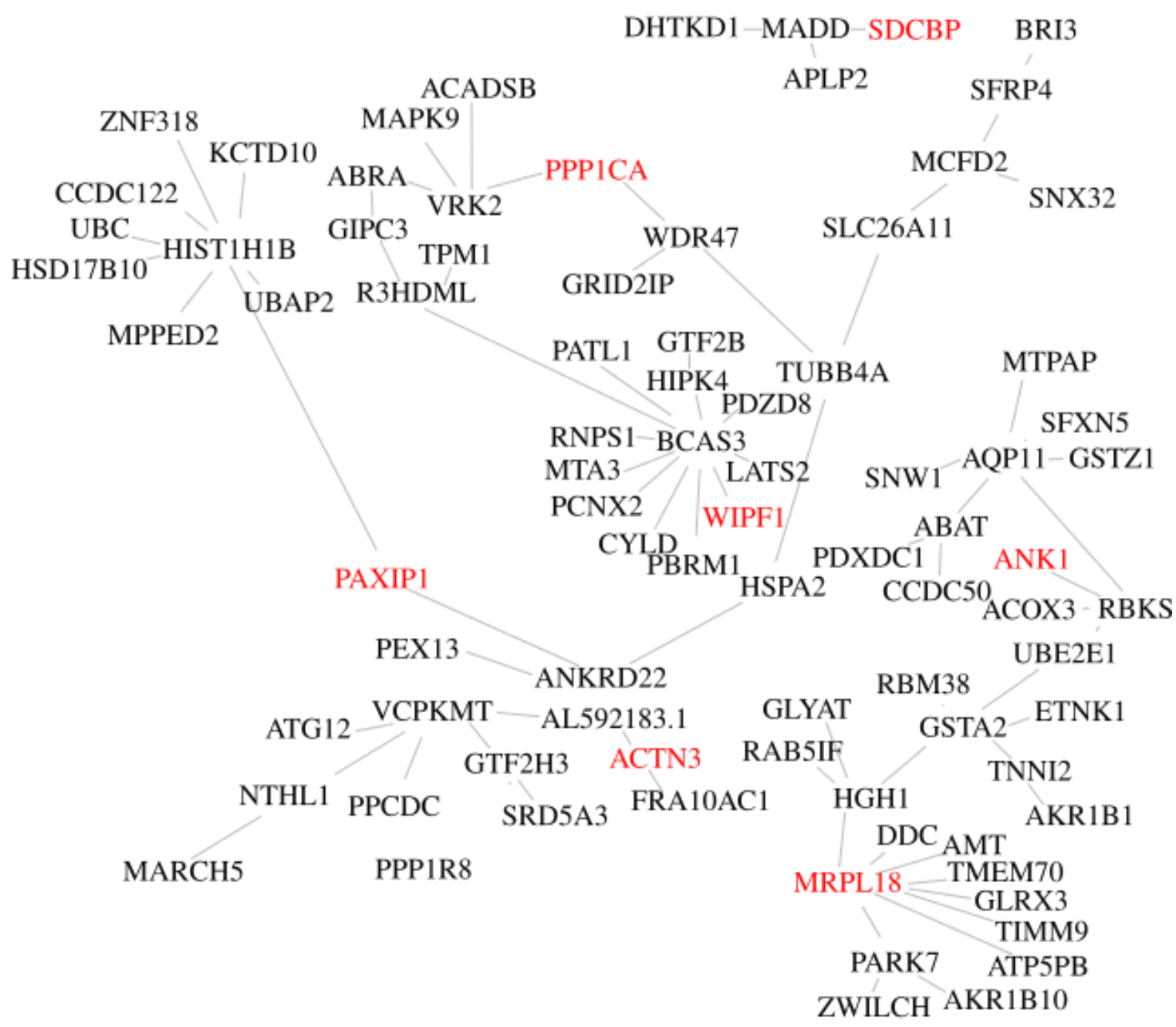

Supplement Figure 2b: Gene interactions observed in worm. The figure was prepared analogously to Supplement Figure 2a from gene interactions observed in the worm. Gene names were mapped to human orthologs for an easier comparison between species. 


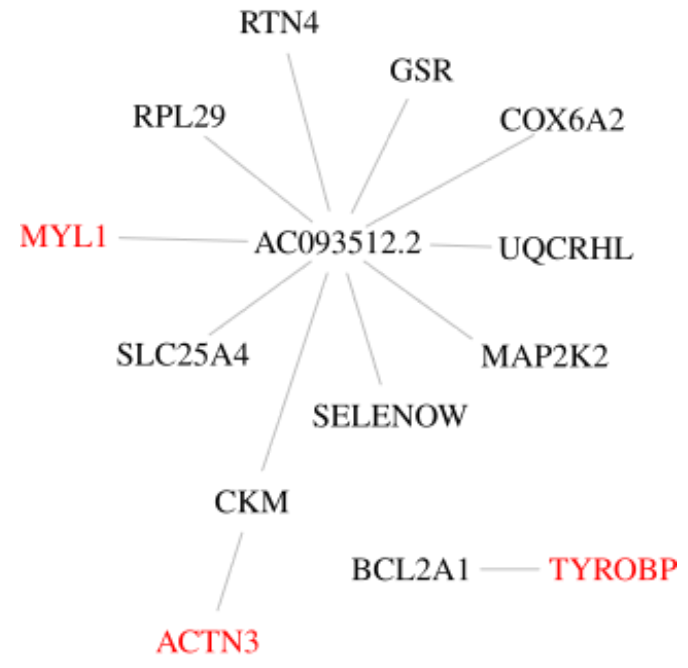

Supplement Figure 2c: Gene interactions observed in rat.

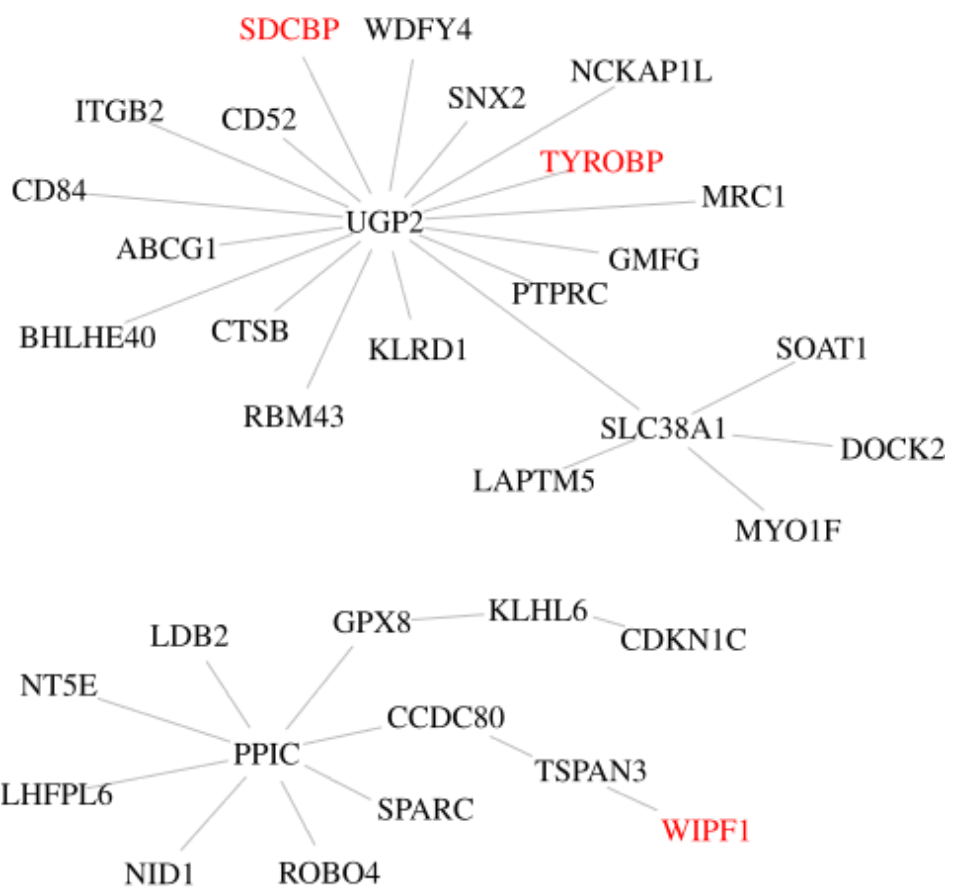

Supplement Figure 2d: Gene interactions observed in mouse. 
bioRxiv preprint doi: https://doi.org/10.1101/2021.04.08.439030; this version posted April 10, 2021. The copyright holder for this preprint (which was not certified by peer review) is the author/funder, who has granted bioRxiv a license to display the preprint in perpetuity. It is made available under aCC-BY 4.0 International license.

\begin{tabular}{|c|c|c|c|c|c|c|c|c|c|c|c|c|c|c|c|c|}
\hline GO:MF & & stats & & & & & & & & & & & & & & \\
\hline Term name & Term ID & $P_{\text {adj }}$ & $0^{-\log _{10}\left(\mathrm{P}_{\text {adj }}\right)}$ & $\leq 16$ & 总 & 喜 & 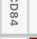 & 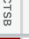 & 法 & 垔 & गี & 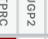 & 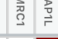 & 0 雾 & 兽 & 峞 \\
\hline protein-containing complex binding & GO:0044877 & $2.774 \times 10^{-2}$ & & & & & & & & & & & & & & \\
\hline & & & & & & & & & 1 of 1 & & & $<\mathrm{Pa}$ & Page 10 & of 1 & & \\
\hline GO:BP & & stats & & & & & & & & & & & & & & \\
\hline Term name & Term ID & $P_{\text {adj }}$ & $0^{-\log _{10}\left(P_{a d j}\right)}$ & s16 & 惫 & 总 & 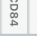 & 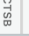 & 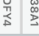 & 至 & 금 & 勇 & 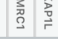 & 需 & 总 & $\begin{array}{l}\text { 范 } \\
\underline{Q}\end{array}$ \\
\hline leukocyte mediated immunity & GO:0002443 & $1.375 \times 10^{-3}$ & & & & & & & & & & & & & & \\
\hline leukocyte degranulation & GO:0043299 & $1.480 \times 10^{-3}$ & & & & & & & & & & & & & & \\
\hline myeloid cell activation involved in immune response & GO:0002275 & $1.647 \times 10^{-3}$ & . & & & & & & & & & & & & & \\
\hline myeloid leukocyte mediated immunity & GO:0002444 & $1.774 \times 10^{-3}$ & & & & & & & & & & & & & & \\
\hline myeloid leukocyte activation & GO:0002274 & $5.387 \times 10^{-3}$ & 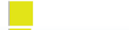 & & & & & & & & & & & & & \\
\hline leukocyte activation involved in immune response & GO:0002366 & $7.896 \times 10^{-3}$ & 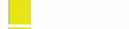 & & & & & & & & & & & & & \\
\hline cell activation involved in immune response & GO:0002263 & $8.153 \times 10^{-3}$ & & & & & & & & & & & & & & \\
\hline regulated exocytosis & GO:0045055 & $1.450 \times 10^{-2}$ & ( & & & & & & & & & & & & & \\
\hline positive regulation of gamma-delta $T$ cell differentiation & GO:0045588 & $1.513 \times 10^{-2}$ & - & & & & & & & & & & & & & \\
\hline immune effector process & GO:0002252 & $1.810 \times 10^{-2}$ & 口 & & & & & & & & & & & & & \\
\hline positive regulation of gamma-delta $T$ cell activation & GO:0046645 & $2.017 \times 10^{-2}$ & L & & & & & & & & & & & & & \\
\hline neutrophil degranulation & GO:0043312 & $2.191 \times 10^{-2}$ & L & & & & & & & & & & & & & \\
\hline neutrophil activation involved in immune response & GO:0002283 & $2.258 \times 10^{-2}$ & L & & & & & & & & & & & & & \\
\hline neutrophil mediated immunity & GO:0002446 & $2.515 \times 10^{-2}$ & 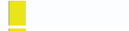 & & & & & & & & & & & & & \\
\hline neutrophil activation & GO:0042119 & $2.564 \times 10^{-2}$ & L & & & & & & & & & & & & & \\
\hline regulation of gamma-delta $T$ cell differentiation & GO:0045586 & $2.592 \times 10^{-2}$ & L & & & & & & & & & & & & & \\
\hline granulocyte activation & GO:0036230 & $2.743 \times 10^{-2}$ & L & & & & & & & & & & & & & \\
\hline secretion by cell & GO:0032940 & $2.754 \times 10^{-2}$ & L & & & & & & & & & & & & & \\
\hline regulation of gamma-delta $T$ cell activation & GO:0046643 & $3.239 \times 10^{-2}$ & 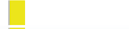 & & & & & & & & & & & & & \\
\hline exocytosis & GO:0006887 & $3.270 \times 10^{-2}$ & 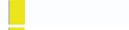 & & & & & & & & & & & & & \\
\hline export from cell & GO:0140352 & $3.535 \times 10^{-2}$ & 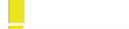 & & & & & & & & & & & & & \\
\hline gamma-delta $T$ cell differentiation & GO:0042492 & $4.747 \times 10^{-2}$ & [ & & & & & & & & & & & & & \\
\hline & & & & & & & & 22 & of 22 & & & $<\mathrm{Pa}$ & Page 10 & of 1 & & \\
\hline GO:CC & & stats & & & & & & & & & & & & & & \\
\hline Term name & Term ID & $P_{\text {adj }}$ & $0^{-\log _{10}\left(p_{\text {adj }}\right)}$ & $\leq 16$ & 总 & $\sum_{\mathrm{L}}^{\mathrm{L}}$ & 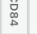 & 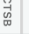 & 焉 & 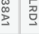 & 胥 & 勇 & 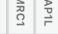 & ت & 孞 & 8 \\
\hline external side of plasma membrane & GO:0009897 & $2.121 \times 10^{-5}$ & & & & & & & & & & & & & & \\
\hline cell surface & GO:0009986 & $1.031 \times 10^{-4}$ & & & & . & & & & & & & & & & \\
\hline side of membrane & GO:0098552 & $2.327 \times 10^{-4}$ & 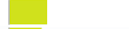 & & & . & & & & & & 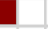 & & & & \\
\hline ficolin-1-rich granule & GO:0101002 & $7.090 \times 10^{-4}$ & 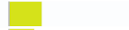 & & & & & & & & & & & & & \\
\hline vesicle & GO:0031982 & $3.815 \times 10^{-3}$ & 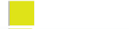 & & & & & & & & & & & & & \\
\hline cytoplasmic vesicle & GO:0031410 & $6.422 \times 10^{-3}$ & & & & & & & & & & & & & & \\
\hline intracellular vesicle & GO:0097708 & $6.500 \times 10^{-3}$ & & & & & & & & & & & & & & \\
\hline intrinsic component of plasma membrane & GO:0031226 & $6.681 \times 10^{-3}$ & & & & . & & & & & & & & & & \\
\hline secretory granule & GO:0030141 & $2.167 \times 10^{-2}$ & 1 & & & & & & & & & & & & & \\
\hline & & & & & & & & to $\mathrm{s}$ & 9 of 9 & & & $<\mathrm{Pa}$ & Page 10 & of 1 & & \\
\hline REAC & & stats & & & & & & & & & & & & & & \\
\hline Term name & Term ID & $P_{\text {adj }}$ & $0^{-\log _{10}\left(p_{\text {adj }}\right)}$ & $\leq 16$ & 疍 & 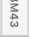 & 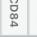 & 产 & \begin{tabular}{l} 
量 \\
\hdashline
\end{tabular} & ᄅِ & 胥 & 矛苋总 & 勇 & 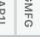 & & 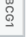 \\
\hline Neutrophil degranulation & REAC:R-HSA- $6 \ldots$ & $3.042 \times 10^{-2}$ & & & & & & & & & & & & & & \\
\hline & & & & & & & & 1 to & 1 of 1 & 1 & & $<\mathrm{Pa}$ & Page 10 & of 1 & & \\
\hline WP & & stats & & & & & & & & & & & & & & \\
\hline Term name & Term ID & $P_{\text {adj }}$ & $0^{-\log _{10}\left(P_{\text {adj }}\right)}$ & s16 & 总 & 罯 & 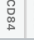 & 胥 & 党 & 递 & 吾 & 勇 & 莺 & 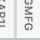 & 总 & 党 \\
\hline TYROBP Causal Network & WP:WP3945 & $2.593 \times 10^{-3}$ & 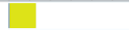 & & & & & & . & & & & & & & \\
\hline & & & & & & & & 1 to & 1 of 1 & 1 & & $<\mathrm{Pa}$ & age 10 & of 1 & & \\
\hline CORUM & & stats & & & & & & & & & & & & & & \\
\hline Term name & Term ID & $P_{\text {adj }}$ & $0^{-\log _{10}\left(P_{\text {adj }}\right)}$ & $\leq 16$ & 总 & $\begin{array}{l}\frac{\mathrm{J}}{\mathrm{z}} \\
\mathrm{\omega} \\
\omega\end{array}$ & 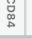 & 㺃 & 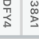 & 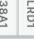 & 곰 & 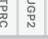 & 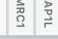 & 点 & 总 & 苟 \\
\hline ITGB2-RACK1 complex & CORUM:7013 & $4.999 \times 10^{-2}$ & & & & & & & & & & & & & & \\
\hline
\end{tabular}

Supplement Figure 3a: g:Profiler GSEA on genes connecting hub genes TYROBP and SDCBP. 
bioRxiv preprint doi: https://doi.org/10.1101/2021.04.08.439030; this version posted April 10, 2021. The copyright holder for this preprint (which was not certified by peer review) is the author/funder, who has granted bioRxiv a license to display the preprint in perpetuity. It is made available under aCC-BY 4.0 International license.

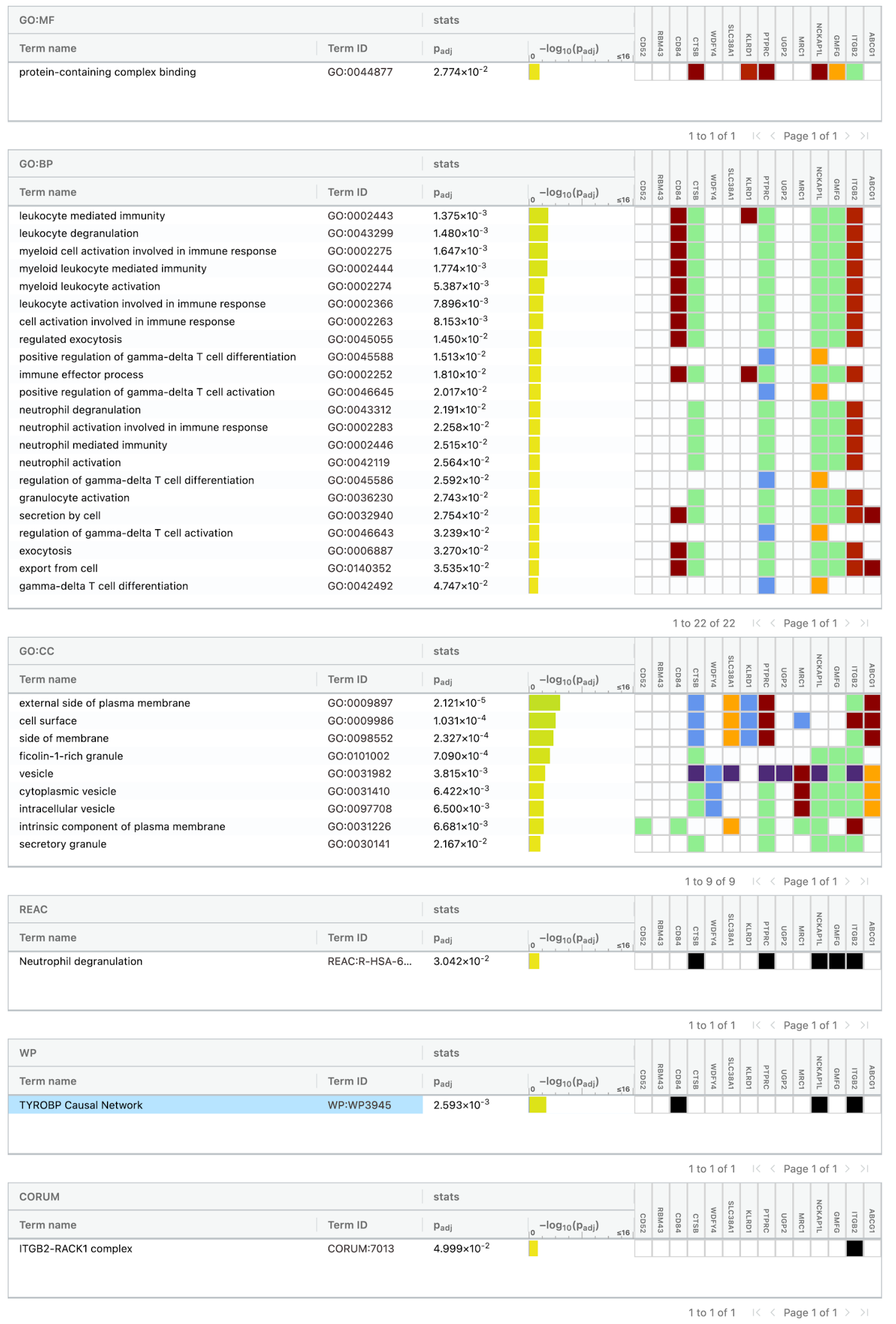

Supplement Figure 3b: g:Profiler GSEA on genes connecting hub genes MYL1 and SKIV2L. 
bioRxiv preprint doi: https://doi.org/10.1101/2021.04.08.439030; this version posted April 10, 2021. The copyright holder for this preprint (which was not certified by peer review) is the author/funder, who has granted bioRxiv a license to display the preprint in perpetuity. It is made available under aCC-BY 4.0 International license.

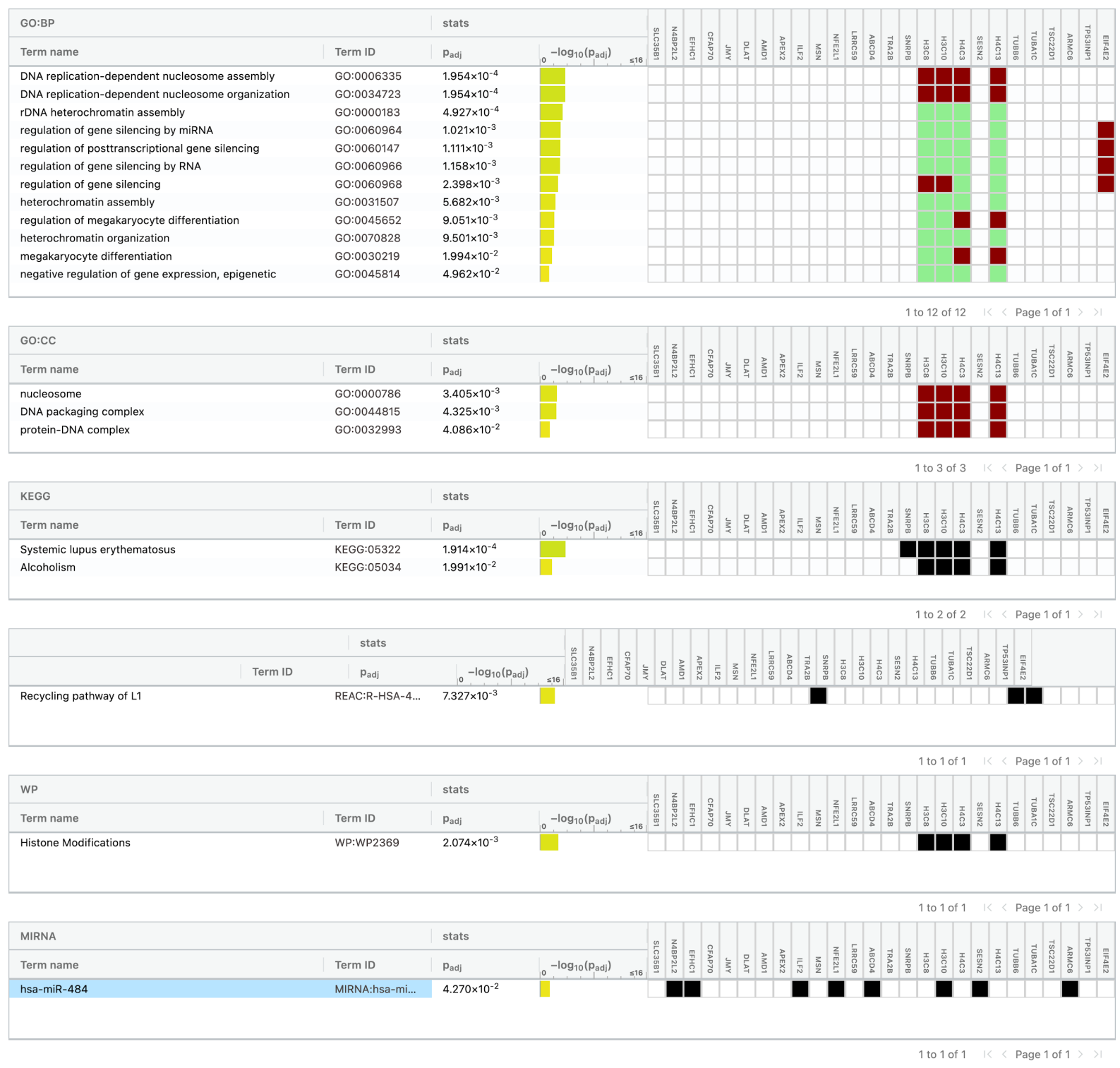

Supplement Figure 3c: g:Profiler GSEA on genes connecting hub genes TUBG1 and PPP1CA. 


\section{Tables}

\section{Supplement Table 1: Genes correlating with eigengene representation (module membership) of those} modules that are correlating with the health score. The table lists all genes that appear in at least two experiments among the top 30 and a $P$ value below 0.05 . If the expression of the gene correlates positively with the health score then the gene is tagged as positive. The columns "cor" and "P val" list the values as determined by WGCNA. A negative correlation with a positive tag indicates that eigengene of the module is negatively correlated with the health score.

\begin{tabular}{|c|c|c|c|c|c|}
\hline Gene & health & cor & P val & Experiment & module \\
\hline 0610006I08Rik & negative & 0.907 & $4.64 \mathrm{e}-05$ & E-GEOD-19102 & darkmagenta \\
\hline 06100९6I08Rik & negative & 0.942 & $4.57 e-06$ & E-GEOD-19102 & skyblue 3 \\
\hline 2010107E@4Rik & positive & 0.951 & $6.24 \mathrm{e}-19$ & E-GEOD- 55272 & black \\
\hline 2010107E@4Rik & positive & -0.947 & $2.10 \mathrm{e}-18$ & E-GEOD- 55272 & magenta \\
\hline ABAT & positive & 0.988 & $2.21 e-18$ & E-GEOD-30505 & blue \\
\hline ABAT & positive & $-\odot .980$ & $1.42 \mathrm{e}-12$ & E-GEOD- 42192 & turquoise \\
\hline ABCG1 & negative & $-\odot .90 \odot$ & $6.76 e-05$ & E-GEOD-19102 & sienna2 \\
\hline ABCG1 & negative & 0.974 & $1.68 \mathrm{e}-23$ & E-GEOD- 55272 & red \\
\hline ABRA & negative & 0.996 & $4.41 e-12$ & E-GEOD- 43864 & brown \\
\hline ABRA & negative & 0.989 & $2.90 \mathrm{e}-06$ & E-GEOD-57739 & turquoise \\
\hline ABRA & positive & -0.968 & $1.12 \mathrm{e}-14$ & E-MTAB-1333 & blue \\
\hline abu-14 & positive & 0.993 & $5.68 e-21$ & E-GEOD-30505 & turquoise \\
\hline abu-14 & positive & $\odot .999$ & $7.55 e-07$ & E-GEOD- 9246 & turquoise \\
\hline AC068831.7 & negative & $-\odot .868$ & $2.48 \mathrm{e}-04$ & E-GEOD-19102 & yellow3 \\
\hline AC068831.7 & negative & 0.986 & $1.28 e-18$ & E-MTAB-1333 & turquoise \\
\hline AC106774.4 & negative & -0.873 & $2.13 e-04$ & E-MEXP-1810 & plum1 \\
\hline AC106774.4 & negative & 0.938 & $6.73 e-06$ & E-MEXP- 1810 & royalblue \\
\hline ADAM10 & negative & $-\odot .871$ & $7.20 \mathrm{e}-\odot 9$ & E-GEOD- 34773 & greenyellow \\
\hline ADAM10 & positive & 0.998 & $4.87 e-13$ & E-GEOD - 43864 & turquoise \\
\hline AG01 & negative & $-\odot .995$ & $2.14 \mathrm{e}-\odot 9$ & E-GEOD-32339 & blue \\
\hline AG01 & negative & $-\odot .879$ & $1.53 e-08$ & E-MTAB-1333 & black \\
\hline ain-1 & negative & 0.921 & $4.24 \mathrm{e}-04$ & E-GEOD- 8696 & cyan \\
\hline ain-1 & negative & 0.965 & $2.56 e-05$ & E-GEOD- 8696 & royalblue \\
\hline APBB1IP & positive & 0.987 & $2.78 e-09$ & E-GEOD-54853-CEL & yellow \\
\hline APBB1IP & negative & 0.970 & $1.68 \mathrm{e}-07$ & E-MTA-B6578 & blue \\
\hline AQP11 & positive & $\odot .997$ & $2.57 e-24$ & E-GEOD-30505 & blue \\
\hline AQP11 & negative & 0.951 & $1.98 e-06$ & E-MEXP-1810 & brown \\
\hline ARMC1 & positive & $-\odot .850$ & $3.97 e-08$ & E-GEOD- 34773 & darkgrey \\
\hline ARMC1 & positive & 0.874 & $5.48 e-\odot 9$ & E-GEOD- 34773 & greenyellow \\
\hline asns-2 & negative & -0.993 & $7.01 \mathrm{e}-05$ & E-GEOD- 51502 & black \\
\hline asns-2 & positive & 0.984 & $8.21 \mathrm{e}-09$ & EGEOD54853-CEL & brown \\
\hline ATP6V1B2 & negative & 0.978 & $4.00 \mathrm{e}-\odot 8$ & E-GEOD- 43864 & paleturquoise \\
\hline ATP6V1B2 & negative & 0.967 & $2.76 e-\odot 7$ & E-GEOD - 43864 & paleturquoise \\
\hline ATP6V1B2 & positive & 0.999 & $2.07 e-06$ & E-GEOD- 9246 & turquoise \\
\hline B2M & negative & 0.927 & 1. $03 e-11$ & E-GEOD- 34773 & lightyellow \\
\hline B2M & negative & 0.922 & $2.13 e-11$ & E-GEOD- 34773 & lightyellow \\
\hline B2M & negative & $\odot .975$ & $6.82 \mathrm{e}-08$ & EMTAB6578 & blue \\
\hline $\mathrm{CO} 2 \mathrm{E} 7.6$ & positive & 0.993 & $4.20 \mathrm{e}-21$ & E-GEOD- 30505 & turquoise \\
\hline $\mathrm{C} \odot 2 \mathrm{E} 7.6$ & positive & 0.990 & $9.63 e-10$ & E-GEOD- 43864 & yellow \\
\hline с०9в9. 2 & negative & 0.990 & $2.56 e-06$ & E-GEOD- 57739 & turquoise \\
\hline с०9в9. 2 & positive & 0.989 & 1. $36 \mathrm{e}-19$ & E-MTAB-1333 & yellow \\
\hline $\mathrm{C} 26 \mathrm{~F} 1.1$ & positive & $\odot .989$ & $1.13 e-09$ & E-GEOD - 43864 & yellow \\
\hline $\mathrm{C} 26 \mathrm{~F} 1.1$ & negative & $\odot .982$ & $4.60 \mathrm{e}-04$ & E-GEOD-51502 & turquoise \\
\hline
\end{tabular}




\begin{tabular}{|c|c|c|c|c|c|}
\hline C46F2.1 & negative & -0.869 & $2.45 e-04$ & E-MEXP- 1810 & plum1 \\
\hline C46F2. 1 & negative & 0.921 & $2.15 e-05$ & E-MEXP- 1810 & royalblue \\
\hline C46G7.1 & positive & $-\odot .979$ & $1.62 \mathrm{e}-12$ & E-GEOD - 42192 & turquoise \\
\hline C46G7.1 & negative & $\odot .928$ & $8.98 e-04$ & E-GEOD-57739 & darkgreen \\
\hline CAD & negative & -0.875 & $1.93 e-04$ & E-MEXP - 1810 & plum1 \\
\hline CAD & negative & $\odot .902$ & $6.02 e-05$ & E-MEXP - 1810 & royalblue \\
\hline CD151 & negative & 0.934 & $8.51 e-06$ & E-GEOD- 19102 & darkmagenta \\
\hline CD151 & negative & -0.905 & $2.28 \mathrm{e}-10$ & E-GEOD-34773 & $\tan$ \\
\hline CEBPB & positive & $\odot .940$ & $1.65 e-04$ & E-GEOD-38062 & salmon \\
\hline CEBPB & negative & 0.812 & $5.27 e-08$ & E-GEOD - 40936 & grey \\
\hline CLIC5 & negative & 0.842 & $6.00 \mathrm{e}-04$ & E-GEOD-19102 & green3 \\
\hline CLIC5 & negative & -0.883 & $2.42 \mathrm{e}-09$ & E-GEOD-34773 & greenyellow \\
\hline comp-1 & negative & $\odot .991$ & $2.09 e-06$ & E-GEOD - 57739 & turquoise \\
\hline comp-1 & positive & $\odot .991$ & $9.50 \mathrm{e}-21$ & E-MTAB - 1333 & yellow \\
\hline c0X15 & positive & $-\odot .89 \odot$ & $1.19 \mathrm{e}-09$ & E-GEOD- 34773 & darkgrey \\
\hline $\operatorname{cox} 15$ & positive & -0.879 & $3.61 \mathrm{e}-09$ & E-GEOD-34773 & darkgrey \\
\hline c0X15 & positive & $\odot .923$ & $1.79 e-11$ & E-GEOD - 34773 & greenyellow \\
\hline $\mathrm{cpg}-2$ & negative & -0.994 & $5.19 e-09$ & E-GEOD-32339 & blue \\
\hline $\mathrm{cpg}-2$ & positive & $\odot .961$ & $3.76 e-05$ & E-GEOD-8696 & red \\
\hline CRB1 & negative & -0.958 & $1.85 e-04$ & E-GEOD-57739 & darkorange \\
\hline CRB1 & positive & $\odot .989$ & $1.48 \mathrm{e}-\odot 9$ & EGEOD54853-CEL & yellow \\
\hline CREBBP & negative & $\odot .953$ & $1.96 \mathrm{e}-05$ & E-GEOD-32339 & pink \\
\hline CREBBP & negative & $\odot .937$ & $1.75 e-12$ & E-GEOD-34773 & red \\
\hline CREBBP & negative & 0.958 & $4.89 e-05$ & E-GEOD- 8696 & purple \\
\hline D2062.7 & positive & -0.969 & $4.07 e-11$ & E-GEOD- 42192 & blue \\
\hline D2062.7 & positive & $\odot .985$ & $1.99 \mathrm{e}-18$ & E-MTAB-1333 & yellow \\
\hline DCP2 & negative & 0.928 & $1.74 \mathrm{e}-10$ & E-GEOD- 30505 & black \\
\hline DCP2 & negative & -0.997 & $2.13 e-10$ & E-GEOD-32339 & blue \\
\hline DDX4 & positive & $-\odot .998$ & $3.10 \mathrm{e}-13$ & E-GEOD- 43864 & blue \\
\hline DDX4 & negative & -0.877 & $1.77 \mathrm{e}-04$ & E-MEXP- 1810 & lightcyan \\
\hline DEPDC1B & negative & $\bullet .915$ & $9.48 e-10$ & E-GEOD- $305 \odot 5$ & black \\
\hline DEPDC1B & positive & -0.934 & $2.28 \mathrm{e}-\odot 4$ & E-GEOD- 8696 & cyan \\
\hline dnj-3 & positive & 0.940 & $5.49 \mathrm{e}-06$ & E-GEOD - 43864 & royalblue \\
\hline$d n j-3$ & negative & $\odot .924$ & $1.05 e-03$ & E-GEOD- 57739 & darkgreen \\
\hline $\operatorname{dnj}-3$ & negative & $\odot .974$ & $9.23 e-16$ & E-MTAB-1333 & brown \\
\hline DRG1 & negative & $\odot .993$ & $6.92 \mathrm{e}-05$ & E-GEOD- 51502 & turquoise \\
\hline DRG1 & negative & 0.925 & $1.64 \mathrm{e}-05$ & E-MEXP - 1810 & brown \\
\hline EEF1B2 & negative & -0.866 & $2.71 \mathrm{e}-04$ & E-GEOD- 19102 & deeppink \\
\hline EEF1B2 & positive & 0.948 & $1.93 e-13$ & E-GEOD - 34773 & green \\
\hline egg-2 & positive & -0.998 & $8.73 e-14$ & E-GEOD - 43864 & blue \\
\hline egg-2 & positive & -0.998 & $2.95 e-13$ & E-GEOD - 43864 & blue \\
\hline egg-2 & positive & $\odot .964$ & $2.85 e-05$ & E-GEOD-8696 & red \\
\hline EIF3F & positive & -0.929 & $7.24 \mathrm{e}-12$ & E-GEOD-34773 & purple \\
\hline EIF3F & positive & $\odot .999$ & $9.64 \mathrm{e}-07$ & E-GEOD- 9246 & turquoise \\
\hline EMC3 & negative & -0.915 & $5.49 e-04$ & E-GEOD-38062 & darkgreen \\
\hline EMC3 & negative & 0.954 & $6.54 \mathrm{e}-05$ & E-GEOD-38062 & plum1 \\
\hline F45D3. 4 & positive & 0.935 & $8.05 e-06$ & E-MEXP - 1810 & darkmagenta \\
\hline F45D3. 4 & positive & -0.917 & $2.69 e-05$ & E-MEXP- 1810 & royalblue \\
\hline F55A3. 2 & positive & $\odot .867$ & $2.62 \mathrm{e}-04$ & E-MEXP- 1810 & darkmagenta \\
\hline F55A3. 2 & positive & 0.876 & $1.89 \mathrm{e}-04$ & E-MEXP - 1810 & darkolivegreen \\
\hline FBLN7 & negative & 0.877 & $1.83 e-04$ & E-GEOD- 19102 & green3 \\
\hline FBLN7 & negative & $\odot .909$ & $1.37 e-10$ & E-GEOD-34773 & magenta \\
\hline $\mathrm{fkb}-7$ & positive & -0.995 & $4.39 e-05$ & E-GEOD- 51502 & turquoise \\
\hline $\mathrm{fkb}-7$ & positive & $\odot .965$ & $1.05 e-04$ & E-GEOD- 57739 & sienna3 \\
\hline
\end{tabular}




\begin{tabular}{|c|c|c|c|c|c|}
\hline$f l p-15$ & positive & 0.959 & $8.29 \mathrm{e}-07$ & E-MEXP - 1810 & plum1 \\
\hline$f l p-15$ & positive & $\odot .914$ & $3.14 \mathrm{e}-05$ & E-MEXP- 1810 & plum1 \\
\hline$f l p-15$ & positive & -0.898 & $7.43 e-05$ & E-MEXP - 1810 & royalblue \\
\hline GMFG & negative & $\odot .892$ & $9.67 e-05$ & E-GEOD- 19102 & darkmagenta \\
\hline GMFG & negative & 0.984 & $6.89 e-27$ & E-GEOD - 55272 & red \\
\hline GNG10 & legative & 0.927 & $1.40 \mathrm{e}-05$ & E-GEOD-19102 & darkmagenta \\
\hline GNG10 & positive & $\odot .959$ & $3.66 e-20$ & E-GEOD - 55272 & yellow \\
\hline GPR142 & negative & 0.990 & $7.71 e-10$ & E-GEOD - 43864 & lightgreen \\
\hline GPR142 & negative & $\odot .979$ & $3.46 \mathrm{e}-\odot 8$ & E-GEOD - 43864 & lightgreen \\
\hline GPR142 & negative & 0.925 & $3.56 \mathrm{e}-04$ & E-GEOD- 8696 & cyan \\
\hline grl-7 & positive & $\odot .992$ & $4.32 e-20$ & E-GEOD-30505 & turquoise \\
\hline grl-7 & positive & $\odot .993$ & $1.22 \mathrm{e}-10$ & E-GEOD - 43864 & yellow \\
\hline grl-7 & positive & 0.991 & $3.61 e-10$ & E-GEOD - 43864 & yellow \\
\hline grl-7 & positive & 0.991 & $3.91 e-10$ & E-GEOD - 43864 & yellow \\
\hline GSTA2 & positive & 0.992 & $3.59 e-20$ & E-GEOD-30505 & blue \\
\hline GSTA2 & negative & 0.976 & $6.93 e-06$ & E-GEOD- 8696 & purple \\
\hline GSTA2 & negative & 0.953 & $1.73 \mathrm{e}-06$ & E-MEXP-1810 & brown \\
\hline $\mathrm{H} 2-\mathrm{D} 1$ & negative & 0.951 & $9.09 \mathrm{e}-14$ & E-GEOD-34773 & lightyellow \\
\hline H2-D1 & negative & 0.948 & $1.95 e-13$ & E-GEOD- 34773 & lightyellow \\
\hline H2-D1 & negative & 0.941 & $9.01 e-13$ & E-GEOD-34773 & lightyellow \\
\hline H2-D1 & negative & 0.894 & $7.30 \mathrm{e}-10$ & E-GEOD-34773 & lightyellow \\
\hline H2 - D1 & negative & $\odot .974$ & $9.03 e-\odot 8$ & EMTAB6578 & blue \\
\hline $42 \mathrm{~K} 12.3$ & positive & 0.992 & $2.23 e-20$ & E-GEOD-30505 & turquoise \\
\hline $42 K 12.3$ & positive & 0.988 & $2.15 e-04$ & E-GEOD - 51502 & blue \\
\hline HACL1 & positive & $\odot .881$ & $1.55 e-\odot 4$ & E-MEXP-1810 & plum1 \\
\hline HACL1 & positive & -0.963 & $5.25 e-07$ & E-MEXP - 1810 & royalblue \\
\hline HACL1 & positive & -0.908 & $4.46 \mathrm{e}-\odot 5$ & E-MEXP - 1810 & royalblue \\
\hline HSDL2 & positive & 0.940 & $5.23 e-04$ & E-GEOD - 57739 & darkorange \\
\hline HSDL2 & positive & 0.949 & $2.39 \mathrm{e}-06$ & E-MEXP- 1810 & lightcyan \\
\hline IHH & negative & 0.933 & $2.34 \mathrm{e}-04$ & E-GEOD - 8696 & cyan \\
\hline IHH & positive & $\odot .999$ & $2.32 \mathrm{e}-\odot 6$ & E-GEOD- 9246 & turquoise \\
\hline INTS12 & negative & -0.845 & $5.42 \mathrm{e}-04$ & E-GEOD- 19102 & yellow3 \\
\hline INTS12 & positive & -0.980 & $2.32 \mathrm{e}-08$ & E-GEOD - 43864 & paleturquoise \\
\hline $\mathrm{K} \odot 8 \mathrm{C} 9.2$ & negative & 0.997 & $8.50 \mathrm{e}-13$ & E-GEOD - 43864 & brown \\
\hline K๑8C9. 2 & positive & 0.986 & $1.88 \mathrm{e}-18$ & E-MTAB-1333 & yellow \\
\hline KPNA3 & negative & 0.932 & $4.18 e-12$ & E-GEOD - 34773 & red \\
\hline KPNA3 & positive & $\odot .999$ & $2.92 \mathrm{e}-06$ & E-GEOD- 9246 & turquoise \\
\hline let -2 & positive & $\odot .992$ & $1.36 \mathrm{e}-20$ & E-GEOD-30505 & blue \\
\hline let -2 & positive & -0.979 & $1.83 e-12$ & E-GEOD - 42192 & turquoise \\
\hline LIAS & positive & -0.921 & $2.67 e-11$ & E-GEOD - 34773 & black \\
\hline LIAS & positive & $\odot .880$ & $3.27 \mathrm{e}-\odot 9$ & E-GEOD - 34773 & $\tan$ \\
\hline LIN28A & positive & $-\odot .998$ & $1.06 \mathrm{e}-13$ & E-GEOD- 43864 & blue \\
\hline LIN28A & positive & -0.998 & $2.15 e-13$ & E-GEOD - 43864 & blue \\
\hline LIN28A & negati & -0.877 & $1.78 \mathrm{e}-\odot 4$ & E-MEXP-1810 & darkolivegreen \\
\hline MARCKS & negative & $\odot .967$ & $3.10 \mathrm{e}-07$ & E-GEOD- 19102 & blue \\
\hline MARCKS & negative & $\odot .918$ & $4.08 e-11$ & E-GEOD - 34773 & magenta \\
\hline MEX3C & negative & -0.994 & $7.28 e-\odot 9$ & E-GEOD-32339 & blue \\
\hline MEX3C & negative & $\odot .948$ & $6.71 \mathrm{e}-13$ & E-GEOD- 38012 & yellow \\
\hline mig- 6 & positive & $-\odot .978$ & $2.21 \mathrm{e}-12$ & E-GEOD - 42192 & turquoise \\
\hline $\operatorname{mig}-6$ & positive & 0.984 & $8.04 \mathrm{e}-\odot 9$ & EGEOD54853-CEL & yellow \\
\hline MRAS & positive & $\odot .989$ & $5.85 e-19$ & E-GEOD-30505 & blue \\
\hline MRAS & positive & -0.965 & $3.01 e-14$ & E-MTAB-1333 & blue \\
\hline MRPL13 & positive & -0.886 & $1.74 \mathrm{e}-\odot 9$ & E-GEOD - 34773 & kgrey \\
\hline MRPL13 & positive & -0.878 & $3.75 \mathrm{e}-\odot 9$ & E-GEOD - 34773 & darkgrey \\
\hline
\end{tabular}




\begin{tabular}{|c|c|c|c|c|c|}
\hline MRPL13 & positive & $\odot .867$ & $9.86 e-09$ & E-GEOD-34773 & greenyellow \\
\hline MRPL19 & positive & -0.869 & $8.64 \mathrm{e}-09$ & E-GEOD- 34773 & darkgrey \\
\hline MRPL19 & negative & $\odot .951$ & $1.96 \mathrm{e}-06$ & E-MEXP - 1810 & brown \\
\hline MRPL30 & negative & 0.888 & $1.13 e-04$ & E-GEOD-19102 & skyblue3 \\
\hline MRPL30 & positive & $\odot .939$ & $2.45 e-17$ & E-GEOD - 55272 & black \\
\hline MTPAP & negative & -0.992 & $3.65 e-20$ & E-GEOD-30505 & blue \\
\hline MTPAP & negative & $-\odot .995$ & $2.69 \mathrm{e}-09$ & E-GEOD- 32339 & blue \\
\hline Myeov2 & positive & 0.931 & $1.71 \mathrm{e}-16$ & E-GEOD - 55272 & black \\
\hline Myeov2 & positive & -0.976 & $5.77 e-24$ & E-GEOD - 55272 & magenta \\
\hline MYL1 & positive & -0.996 & $3.24 \mathrm{e}-25$ & E-GEOD - 38012 & turquoise \\
\hline MYL1 & positive & 0.985 & $1.49 \mathrm{e}-06$ & E-GEOD - 38062 & $\tan$ \\
\hline MYL7 & negative & $\odot .895$ & $8.28 \mathrm{e}-05$ & E-GEOD-19102 & skyblue3 \\
\hline MYL7 & negative & $\odot .901$ & $6.40 \mathrm{e}-05$ & EGEOD54853-MMU & darkturquoise \\
\hline NDUFS1 & positive & 0.862 & $3.07 e-04$ & E-GEOD-19102 & coral1 \\
\hline NDUFS1 & positive & $\odot .877$ & $1.77 \mathrm{e}-04$ & E-GEOD-19102 & lightsteelblue1 \\
\hline $\mathrm{NR} 1 \mathrm{H} 2$ & positive & 0.983 & $1.22 \mathrm{e}-08$ & E-GEOD - 43864 & darkorange \\
\hline NR1H2 & negative & -0.909 & $1.75 e-03$ & E-GEOD - 57739 & sienna3 \\
\hline $\mathrm{NR} 1 \mathrm{H} 2$ & positive & 0.883 & $1.42 \mathrm{e}-04$ & E-MEXP- 1810 & darkolivegreen \\
\hline NR1H2 & positive & $\odot .851$ & $4.51 \mathrm{e}-04$ & E-MEXP- 1810 & darkolivegreen \\
\hline $\mathrm{NR} 1 \mathrm{H} 2$ & positive & $\odot .894$ & $3.95 e-09$ & E-MTAB-1333 & black \\
\hline NRBP1 & negative & 0.855 & $2.64 e-08$ & E-GEOD - 34773 & darkgrey \\
\hline NRBP1 & negative & 0.969 & $4.13 e-22$ & E-GEOD- 55272 & pink \\
\hline Pabpc1 & positive & $-\odot .887$ & $1.21 \mathrm{e}-04$ & E-GEOD - 19102 & darkmagenta \\
\hline Pabpc1 & negative & $\odot .969$ & $2.22 \mathrm{e}-07$ & EMTAB6578 & blue \\
\hline PAXIP1 & positive & $\odot .890$ & $1.03 e-04$ & E-GEOD- 19102 & deeppink \\
\hline PAXIP1 & positive & $\odot .998$ & $2.67 e-13$ & E-GEOD - 43864 & turquoise \\
\hline PCNX2 & negative & $\odot .962$ & $7.78 e-14$ & E-MTAB - 1333 & blue \\
\hline PCNX2 & negative & $\odot .907$ & $4.66 e-05$ & EGEOD54853-MMU & darkturquoise \\
\hline PDCD6 & negative & -0.959 & $8.71 \mathrm{e}-07$ & E-GEOD - 43864 & royalblue \\
\hline PDCD6 & negative & 0.928 & $6.50 \mathrm{e}-11$ & E-MTAB-1333 & green \\
\hline PFAS & positive & -0.858 & $2.13 e-08$ & E-GEOD - 34773 & darkgrey \\
\hline PFAS & positive & 0.941 & $8.58 e-13$ & E-GEOD - 34773 & greenyellow \\
\hline PPIA & positive & -0.975 & $6.83 e-12$ & E-GEOD - 42192 & blue \\
\hline PPIA & negative & $\odot .918$ & $2.52 \mathrm{e}-05$ & E-MEXP - 1810 & royalblue \\
\hline PPIC & negative & $\odot .981$ & $1.67 \mathrm{e}-08$ & E-GEOD-19102 & blue \\
\hline PPIC & negative & $\odot .981$ & $1.97 \mathrm{e}-08$ & E-GEOD-19102 & blue \\
\hline PPIC & negative & $\odot .917$ & $4.55 e-11$ & E-GEOD - 34773 & magenta \\
\hline PPP1CA & positive & $\odot .987$ & $2.48 \mathrm{e}-04$ & E-GEOD- 51502 & black \\
\hline PPP1CA & negative & $\odot .991$ & $1.68 \mathrm{e}-06$ & E-GEOD- 57739 & turquoise \\
\hline PPP1CA & positive & $\odot .993$ & $2.02 \mathrm{e}-14$ & E-GEOD- 66236 & turquoise \\
\hline PPP1CA & positive & $\odot .989$ & $9.26 \mathrm{e}-20$ & E-MTAB-1333 & yellow \\
\hline PPP1CB & positive & -0.979 & $4.67 e-06$ & E-GEOD - 38062 & turquoise \\
\hline PPP1CB & positive & $\odot .999$ & $1.18 \mathrm{e}-06$ & E-GEOD- 9246 & turquoise \\
\hline PP2R3C & negative & $\odot .944$ & $1.38 \mathrm{e}-12$ & E-GEOD - 38012 & yellow \\
\hline PPP2R3C & negative & $\odot .966$ & 1. $31 \mathrm{e}-21$ & E-GEOD- 55272 & pink \\
\hline pqn-32 & positive & $\odot .993$ & $3.79 e-21$ & E-GEOD-30505 & turquoise \\
\hline pqn-32 & positive & $\odot .993$ & $1.60 \mathrm{e}-10$ & E-GEOD - 43864 & yellow \\
\hline pqn-32 & positive & $\odot .989$ & $1.27 \mathrm{e}-09$ & E-GEOD - 43864 & yellow \\
\hline PSMD4 & positive & $\odot .932$ & $9.87 e-06$ & E-GEOD-19102 & lightpink2 \\
\hline PSMD4 & negative & 0.848 & $4.59 e-08$ & E-GEOD - 34773 & darkgrey \\
\hline ptp-2 & negative & -0.937 & $7.07 e-06$ & E-MEXP- 1810 & plum1 \\
\hline ptp-2 & negative & $\odot .932$ & $1.03 e-05$ & E-MEXP- 1810 & royalblue \\
\hline PUM1 & negative & -0.995 & $3.07 e-09$ & E-GEOD - 32339 & blue \\
\hline PUM1 & negative & -0.995 & $3.51 e-09$ & E-GEOD - 32339 & blue \\
\hline
\end{tabular}




\begin{tabular}{|c|c|c|c|}
\hline PUM1 & positive & 0.986 & $9.40 \mathrm{e}-07$ \\
\hline R3HDML & negative & -0.898 & $7.34 \mathrm{e}-05$ \\
\hline २3HDML & ative & 0.928 & $1.33 e-05$ \\
\hline R3HDML & negative & ๑. 916 & $2.80 \mathrm{e}-05$ \\
\hline RAB2A & negative & $\odot .965$ & $6.41 \mathrm{e}-06$ \\
\hline RAB2A & egative & $\odot .960$ & $2.47 \mathrm{e}-20$ \\
\hline RAB31 & gative & 0.952 & $1.77 \mathrm{e}-06$ \\
\hline RAB31 & gative & $\odot .971$ & $1.37 \mathrm{e}-05$ \\
\hline RAD17 & egative & 0.994 & $5.90 \mathrm{e}-\odot 9$ \\
\hline RAD17 & egative & $\odot .982$ & $1.90 \mathrm{e}-17$ \\
\hline RGL1 & egative & 0.956 & $1.25 e-06$ \\
\hline RGL1 & tive & -0.687 & $2.76 \mathrm{e}-05$ \\
\hline RMDN3 & ive & -0.971 & $2.12 \mathrm{e}-11$ \\
\hline RMDN3 & egative & $\odot .999$ & $3.97 e-14$ \\
\hline RMDN3 & legative & 0.996 & $4.43 e-12$ \\
\hline RMDN3 & tive & $\odot .967$ & $2.03 e-05$ \\
\hline RPL11 & ive & ๑. 929 & $7.00 \mathrm{e}-12$ \\
\hline RPL11 & tive & $\odot .963$ & $7.42 \mathrm{e}-21$ \\
\hline RPL13A & ositive & $\odot .936$ & $2.43 e-12$ \\
\hline RPL13A & ositive & $-\odot .959$ & $1.11 \mathrm{e}-14$ \\
\hline RPL23A & tive & 0.934 & $3.34 \mathrm{e}-12$ \\
\hline RPL23A & tive & $\odot .929$ & $7.50 \mathrm{e}-12$ \\
\hline RPL23A & oositive & -0.966 & $1.56 \mathrm{e}-15$ \\
\hline RPL23A & ositive & -0.939 & $1.26 \mathrm{e}-12$ \\
\hline RPL23A & positive & -0.934 & $3.44 \mathrm{e}-12$ \\
\hline RPL27 & positive & 0.930 & $6.54 \mathrm{e}-12$ \\
\hline RPL27 & positive & -0.963 & $4.04 e-15$ \\
\hline Rpl27a & ositive & $\odot .935$ & $2.52 \mathrm{e}-12$ \\
\hline Rpl27a & positive & $\odot .965$ & $2.64 \mathrm{e}-21$ \\
\hline RPL29 & positive & $\odot .940$ & $1.09 \mathrm{e}-12$ \\
\hline RPL29 & positive & $\odot .976$ & $7.35 e-06$ \\
\hline RPS12 & positive & $\odot .942$ & $7.63 e-13$ \\
\hline RPS12 & positive & -0.926 & $1.28 \mathrm{e}-11$ \\
\hline RPS21 & positive & $\odot .954$ & $4.18 \mathrm{e}-14$ \\
\hline RPS21 & positive & 0.937 & $1.87 \mathrm{e}-12$ \\
\hline RPS21 & positive & -0.923 & $1.82 \mathrm{e}-11$ \\
\hline Rps25 & positive & $\odot .960$ & $1.00 \mathrm{e}-14$ \\
\hline Rps25 & positive & $-\odot .927$ & $1.02 \mathrm{e}-11$ \\
\hline Rps29 & positive & $\odot .935$ & $2.90 \mathrm{e}-12$ \\
\hline Rps29 & positive & $-\odot .954$ & $4.47 e-14$ \\
\hline RPS7 & negative & -0.905 & $5.22 \mathrm{e}-05$ \\
\hline RPS7 & positive & $-\odot .923$ & $1.92 \mathrm{e}-11$ \\
\hline RTN2 & egative & $\odot .861$ & $1.66 \mathrm{e}-\odot 8$ \\
\hline RTN2 & positive & $-\odot .995$ & $2.44 \mathrm{e}-24$ \\
\hline RYR1 & positive & $\odot .883$ & $1.43 e-04$ \\
\hline RYR1 & positive & -0.994 & $2.21 e-23$ \\
\hline SCN3B & positive & -0.879 & $1.67 \mathrm{e}-\odot 4$ \\
\hline SCN3B & positive & -0.956 & $5.85 e-05$ \\
\hline SFT2D2 & negative & -0.929 & $2.73 e-16$ \\
\hline SFT2D2 & negative & $\odot .975$ & $8.14 \mathrm{e}-24$ \\
\hline sgo-1 & positive & -0.998 & $1.68 e-13$ \\
\hline sgo-1 & negative & 0.985 & $3.18 \mathrm{e}-18$ \\
\hline SIK1B & negative & $\odot .992$ & $1.18 \mathrm{e}-06$ \\
\hline IK1B & itive & $\odot .989$ & $1.13 \mathrm{e}-19$ \\
\hline
\end{tabular}

E-GEOD - 8696

E-MEXP-1810

E-MEXP- 1810

E-MEXP-1810

E-GEOD- 32339

E-GEOD- 55272

E-GEOD- 19102

E-GEOD- 38062

E-GEOD- 32339

E-MTAB-1333

E-GEOD-19102

E-GEOD - 40936

E-GEOD- 42192

E-GEOD - 43864

E-GEOD- 43864

E-GEOD - 8696

E-GEOD - 34773

E-GEOD- 55272

E-GEOD- 34773

E-GEOD - 34773

E-GEOD - 34773

E-GEOD - 34773

E-GEOD - 34773

E-GEOD - 34773

E-GEOD - 34773

E-GEOD- 34773

E-GEOD- 34773

E-GEOD- 34773

E-GEOD- 55272

E-GEOD- 34773

E-GEOD- 38062

E-GEOD - 34773

E-GEOD - 34773

E-GEOD - 34773

E-GEOD - 34773

E-GEOD - 34773

E-GEOD- 34773

E-GEOD - 34773

E-GEOD- 34773

E-GEOD- 34773

E-GEOD- 19102

E-GEOD- 34773

E-GEOD-34773

E-GEOD-38012

E-GEOD- 19102

E-GEOD- 38012

E-GEOD- 19102

E-GEOD- 38062

E-GEOD- 55272

E-GEOD- 55272

E-GEOD - 43864

E-MTAB-1333

E-GEOD- 57739

E-MTAB-1333 red

plum1

royalblue

royalblue

pink

pink

blue

turquoise

turquoise

turquoise

blue

grey

blue

brown

brown

red

green

yellow

green

purple

green

green

purple

purple

purple

green

purple

green

yellow

green

tan

green

purple

green

green

purple

green

purple

green

purple

deeppink purple

darkgrey

turquoise sienna2

turquoise green3

yellowgreen black magenta blue

turquoise turquoise yellow 


\begin{tabular}{|c|c|c|c|c|c|}
\hline SIX4 & negative & 0.954 & $1.74 \mathrm{e}-12$ & E-GEOD-30505 & red \\
\hline SIX4 & negative & -0.871 & $7.31 e-09$ & E-GEOD - 34773 & greenyellow \\
\hline SKP1 & negative & 0.995 & $2.19 \mathrm{e}-09$ & E-GEOD-32339 & turquoise \\
\hline SKP1 & egative & 0.940 & $9.01 e-12$ & E-MTAB-1333 & green \\
\hline SKP1 & egative & 0.924 & $1.21 \mathrm{e}-10$ & E-MTAB-1333 & green \\
\hline SLC16A9 & ositive & $\odot .989$ & $1.02 \mathrm{e}-18$ & E-GEOD-30505 & blue \\
\hline SLC16A9 & gative & -0.911 & $3.81 e-05$ & E - MEXP - 1810 & darkmagenta \\
\hline SLC7A11 & egative & $\odot .96 \odot$ & $1.19 \mathrm{e}-13$ & E-MTAB-1333 & blue \\
\hline SLC7A11 & ositive & 0.987 & $2.50 \mathrm{e}-\odot 9$ & EGEOD54853-CEL & brown \\
\hline$s m z-2$ & ositive & $-\odot .97 \odot$ & $3.19 e-11$ & E-GEOD - 42192 & blue \\
\hline $\mathrm{smz}-2$ & itive & 0.988 & $2.18 \mathrm{e}-19$ & E-MTAB - 1333 & yellow \\
\hline SNRPD1 & gative & -0.875 & $1.91 \mathrm{e}-04$ & E-GEOD-19102 & lightsteelblue1 \\
\hline SNRPD1 & egative & 0.954 & $6.08 e-13$ & E - MTAB - 1333 & brown \\
\hline somi-1 & ositive & 0.917 & $2.74 \mathrm{e}-05$ & E-MEXP-1810 & plum1 \\
\hline somi-1 & tive & 0.993 & $1.50 \mathrm{e}-10$ & EGEOD54853-CEL & yellow \\
\hline spe-38 & ative & -0.976 & $6.37 e-08$ & E-GEOD - 43864 & darkorange \\
\hline spe-38 & yative & $\odot .992$ & $2.98 \mathrm{e}-10$ & E-GEOD - 43864 & lightgreen \\
\hline SQSTM1 & egative & 0.959 & $1.07 \mathrm{e}-14$ & E-GEOD - 34773 & black \\
\hline SQSTM1 & egative & 0.924 & $3.74 \mathrm{e}-04$ & E-GEOD- 38062 & yellowgreen \\
\hline SQSTM1 & tive & 0.885 & $1.29 \mathrm{e}-\odot 4$ & E-MEXP- 1810 & lightcyan \\
\hline sss-2 & itive & -0.970 & $3.11 \mathrm{e}-11$ & E-GEOD - 42192 & blue \\
\hline sss-2 & sitive & $\odot .990$ & $5.42 e-20$ & E-MTAB - 1333 & yellow \\
\hline T14G11.1 & egative & -0.955 & $2.26 e-\odot 4$ & E-GEOD- 57739 & darkorange \\
\hline T14G11.1 & egative & -0.909 & $7.81 e-10$ & E-MTAB-1333 & black \\
\hline T19D12. 2 & egative & $\odot .979$ & $6.61 \mathrm{e}-04$ & E-GEOD - 51502 & urquoise \\
\hline T19D12. 2 & ositive & -0.892 & $9.42 \mathrm{e}-05$ & E-MEXP- 1810 & royalblue \\
\hline T22B3. 3 & egative & 0.998 & $3.30 \mathrm{e}-08$ & E-GEOD-57739 & turquoise \\
\hline Т22B3. 3 & ositive & 0.989 & $1.42 e-19$ & E-MTAB-1333 & yellow \\
\hline T28B11. 1 & ositive & -0.928 & $1.39 \mathrm{e}-05$ & E-MEXP-1810 & brown \\
\hline T28B11. 1 & egative & $\odot .964$ & $3.65 e-14$ & E-MTAB - 1333 & blue \\
\hline T28H11. 7 & ositive & -0.981 & $8.69 e-13$ & E-GEOD - 42192 & blue \\
\hline T28H11. 7 & ositive & $\odot .987$ & $4.02 e-19$ & E-MTAB-1333 & yellow \\
\hline TGIF2 & ative & 0.964 & $7.01 e-06$ & E-GEOD-32339 & \\
\hline TGIF2 & sitive & 0.883 & $1.08 \mathrm{e}-08$ & E-MTAB-1333 & black \\
\hline TMEM7० & sitive & -0.913 & $8.24 \mathrm{e}-11$ & E-GEOD - 34773 & darkgrey \\
\hline TMEM7० & gative & $\odot .952$ & $1.87 \mathrm{e}-06$ & E-MEXP-1810 & brown \\
\hline TNNI2 & ve & 0.905 & $5.22 e-05$ & E-MEXP-1810 & plum1 \\
\hline TNNI2 & ositive & 0.870 & $2.34 \mathrm{e}-\odot 4$ & E-MEXP- 1810 & plum1 \\
\hline TNNI2 & ositive & $\odot .992$ & $3.43 e-10$ & EGEOD54853-CEL & brown \\
\hline TOMM70 & sitive & -0.917 & $2.70 \mathrm{e}-05$ & E-GEOD-19102 & darkmagenta \\
\hline ТОММ70 & itive & 0.879 & $1.65 e-04$ & E-GEOD-19102 & deeppink \\
\hline TUBG1 & negative & 0.948 & $1.03 e-04$ & E-GEOD-38062 & plum1 \\
\hline TUBG1 & ositive & 0.987 & $1.43 e-12$ & E-GEOD- 66236 & turquoise \\
\hline UBE2E1 & gative & -0.989 & $7.37 e-19$ & E-GEOD-30505 & blue \\
\hline UBE2E1 & negative & -0.993 & $8.90 e-09$ & E-GEOD-32339 & blue \\
\hline UGT3A1 & positive & $-\odot .979$ & $1.55 e-12$ & E-GEOD - 42192 & turquoise \\
\hline UGT3A1 & sitive & 0.935 & $6.68 e-04$ & E-GEOD - 57739 & sienna3 \\
\hline UTY & negative & 0.986 & $2.97 e-04$ & E-GEOD- 51502 & turquoise \\
\hline UTY & ositive & 0.985 & $6.35 e-09$ & EGEOD54853-CEL & yellow \\
\hline VAMP3 & egative & -0.912 & $9.32 e-11$ & E-GEOD-34773 & greenyellow \\
\hline VAMP3 & negative & -0.885 & $1.96 \mathrm{e}-09$ & E-GEOD - 34773 & \\
\hline VRK2 & positive & -0.972 & $1.70 \mathrm{e}-11$ & E-GEOD - 42192 & blc \\
\hline VRK2 & negative & -0.935 & $8.29 \mathrm{e}-06$ & E-GEOD - 43864 & darkorange \\
\hline VRK2 & negative & 0.996 & $1.77 \mathrm{e}-07$ & E-GEOD- 57739 & turquoise \\
\hline
\end{tabular}


bioRxiv preprint doi: https://doi.org/10.1101/2021.04.08.439030; this version posted April 10, 2021. The copyright holder for this preprint (which was not certified by peer review) is the author/funder, who has granted bioRxiv a license to display the preprint in perpetuity. It is made available under aCC-BY 4.0 International license.

\begin{tabular}{|c|c|c|c|c|c|}
\hline VRK2 & negative & $\odot .993$ & $9.81 e-07$ & E-GEOD-57739 & turquoise \\
\hline VRK2 & negative & $\odot .982$ & $2.26 e-17$ & E-MTAB-1333 & turquoise \\
\hline VRK2 & positive & $\odot .990$ & $3.87 e-20$ & E-MTAB-1333 & yellow \\
\hline VRK2 & positive & $\odot .989$ & $1.44 \mathrm{e}-19$ & E-MTAB-1333 & yellow \\
\hline VRK2 & positive & 0.986 & $1.55 e-18$ & E-MTAB-1333 & yellow \\
\hline W03G11. 4 & positive & $\odot .993$ & $1.43 e-10$ & E-GEOD - 43864 & yellow \\
\hline W03G11. 4 & positive & $\odot .990$ & $8.23 e-10$ & E-GEOD - 43864 & yellow \\
\hline W03G11. 4 & positive & $\odot .998$ & $3.84 e-06$ & E-GEOD- 9246 & turquoise \\
\hline W03G11. 4 & positive & $\odot .990$ & $6.47 e-10$ & EGEOD54853-CEL & yellow \\
\hline WDR47 & negative & -0.993 & $6.36 e-05$ & E-GEOD- 51502 & black \\
\hline WDR47 & positive & 0.947 & $2.94 \mathrm{e}-06$ & E-MEXP- 1810 & darkmagenta \\
\hline WIPF1 & ative & 0.954 & $1.55 e-06$ & E-GEOD-19102 & blue \\
\hline WIPF1 & negative & $\odot .919$ & $3.60 \mathrm{e}-11$ & E-GEOD - 34773 & magenta \\
\hline WIPF1 & negative & 0.962 & $6.73 e-14$ & E-MTAB-1333 & blue \\
\hline Y42H9AR . 4 & negative & 0.942 & $2.15 e-11$ & E-GEOD- 30505 & black \\
\hline 142H9AR . 4 & negative & -0.996 & $1.78 \mathrm{e}-09$ & E-GEOD-32339 & blue \\
\hline ZC3H15 & negative & $\odot .982$ & $1.56 e-08$ & E-GEOD- 43864 & midnightblue \\
\hline ZC3H15 & negative & -0.978 & $7.07 e-25$ & E-GEOD- 55272 & yellow \\
\hline ZFP36 & negative & -0.994 & $4.29 e-09$ & E-GEOD-32339 & blue \\
\hline ZFP36 & negative & -0.994 & $4.60 \mathrm{e}-09$ & E-GEOD - 32339 & blue \\
\hline ZFP36 & positive & $\odot .971$ & $1.33 e-05$ & E-GEOD-8696 & red \\
\hline
\end{tabular}

